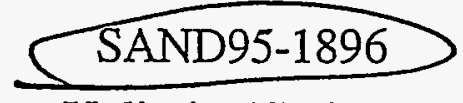

Unlimited Release

Printed January, 1996
RECEIVED

JUL 311996

OSTI

\title{
THREE-DIMENSIONAL MODELING OF FLOW THROUGH FRACTURED TUFF AT FRAN RIDGE
}

\author{
Roger R. Eaton, Clifford K. Ho, \\ Robert J. Glass, Michael J. Nicholl, and Bill W. Arnold \\ Sandia National Laboratories \\ Albuquerque New Mexico 87185
}

\begin{abstract}
Numerical studies have been made of an infiltration experiment at Fran Ridge using the TOUGH 2 code to aid in the selection of computational models for performance assessment. The exercise investigates the capabilities of TOUGH2 to model transient flows through highly fractured tuff and provides a possible means of calibration. Two distinctly different conceptual models were used in the TOUGH2 code, the dual permeability model and the equivalent continuum model. The infiltration test modeled involved the infiltration of dyed ponded water for 36 minutes. The 205 gallon infiltration of water observed in the experiment was subsequently modeled using measured Fran Ridge fracture frequencies, and a specified fracture aperture of $285 \mu \mathrm{m}$. The dual permeability formulation predicted considerable infiltration along the fracture network, which was in agreement with the experimental observations. As expected, minimal fracture penetration of the infiltrating water was calculated using the equivalent continuum model, thus demonstrating that this model is not appropriate for modeling the highly transient experiment. It is therefore recommended that the dual permeability model be given priority when computing high-flux infiltration for use in performance assessmént studies




\section{DISCLAIMER}

Portions of this document may be illegible in electronic image products. Images are produced from the best available original document. 


\section{Preface}

This report was prepared under the Yucca Mountain Site Characterization Project WBS Element 1.2.5.4.1, QA Grading Report \#1.2.5.4.1, Revision 00. The planning document that guided this work activity was WA 0135, Revision 01. 


\section{ACKNOWLEDGMENTS}

The authors would like to thank John H. Gauthier, Vincent Tidwell and Peter Davies for their careful reviews of this report.

7. 


\section{EXECUTIVE SuMMARY}

The purpose of this study is to model the Fran Ridge infiltration experiment using the TOUGH2 flow code (Pruess, 1991) with the dual permeability model option (Pruess, 1983) and the equivalent continuum model option (Peters and Klavetter, 1988). This exercise tests the capabilities of TOUGH2 to model transient flows through a highly fractured in situ region of densely welded, fractured tuff and provides a possible means of calibrating dual permeability parameters used in the code. This type of model evaluation was recommended by Wilson et al. (1994) to aid in model selection of future total system performance assessment groundwater travel time studies. Because of the observed advantages of the dual permeability model over the equivalent continuum model, it is recommended that future performance assessment modeling be made using the dual permeability formulation for transient flow conditions where pressure equilibrium does not exist.

A major outcrop of densely welded, nonlithophysal Topopah Spring Tuff exists on the eastern side of Fran Ridge. This ridge has been selected as the test location for a large in situ block experiment. An integral part of preparation of the ridge for the large block experiment called for the removal of the surrounding country rock such that a $4.5 \mathrm{~m}$ high and $3 \mathrm{~m} \mathrm{x} 3 \mathrm{~m}$ test block remained. Prior to excavating the region adjacent to the large block, 205 gallons of blue dyed water were ponded in a $1.5 \mathrm{~m}$ diameter region on a leveled surface of the surrounding country rock and allowed to infiltrate the subregion. The infiltration process took 36 minutes. The removal of the country rock, in approximately 0.5 $\mathrm{m}$ lifts, provided an opportunity to map the in situ rock fracture patterns and the infiltration paths of the water in an $2.4 \mathrm{~m}$ by $2.4 \mathrm{~m}$ by $4.5 \mathrm{~m}$ ( $8 \mathrm{ft}$ by $8 \mathrm{ft}$ by $15 \mathrm{ft}$ ) deep region. The blue tracer dye used in the experiment indicated ample fracture flows at the $4.5 \mathrm{~m}$ depth. This experiment and the associated mapping was completed by Nicholl and Glass (1995).

The results of the computations showed that the experimental infiltration rate (205 gallons in 36 minutes) could be predicted, within 10\%, using a fracture aperture of $285 \mu \mathrm{m}$ and the dual permeability option in the TOUGH2 code. Water infiltrated the fractures such that the calculated fracture saturation was greater than 0.5 to a depth of $40 \mathrm{~m}$. A total of 640 different materials, based on the observed fracture frequencies, were used in the simulation. When the inner $2.4 \mathrm{~m}$ by $2.4 \mathrm{~m}$ heterogeneous core was modeled with a 
homogeneous average of the fracture frequencies, the calculated infiltration rate decreased, from 225 to 193 gallons. This reasonable agreement implies that the fracture frequency on the subscale of $0.3 \mathrm{~m}$ by $0.3 \mathrm{~m}$ may not be critical for determining a good approximation of total flow at physical scales comparable to this experiment. As expected the results obtained using the equivalent continuum model in the TOUGH2 code did not accurately predict the transient nature of the experiment. This discrepancy is attributed to the nonequilibrium pressure condition that exists between the matrix and fracture materials during the transient portion of the experiment. Equilibrium pressure is the basic assumption in the development of the equivalent continuum model.

In Chapter 1 of this report, the numerical codes and conceptual models being considered for use in calculating the flow of water through Yucca Mountain are outlined. The relevance of these codes to groundwater travel times and total system performance assessment are discussed.

A detailed description of the water infiltration experiments at Fran Ridge is given in Chapter 2. The influence of various flow processes and material parameters on fast-flow paths are discussed in Chapter 3. A one-dimensional sample calculation is used to demonstrate relative importance of processes and parameters.

The development of a block-scale model of fracture flow at Fran Ridge is presented in Chapter 4. Results of calculations using the dual permeability model and equivalent continuum model for the base nominal case and parametric variations of the nominal case are given.

A summary of the results of these calculations and suggestions for future investigations are presented in Chapter 5 . 


\section{Table Of Contents}

1. Introduction

1.1 Problem Statement........................................................................................1-1

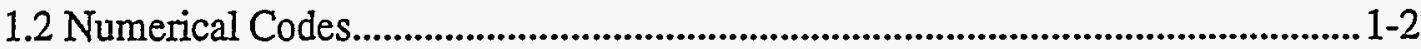

1.3 Alternative Conceptual Models of Fracture Flow ................................................1-3

1.4 Overview of Report................................................................................................. 1-3

2. Summary of an Infiltration Tracer Test Performed at Fran Ridge 2-1

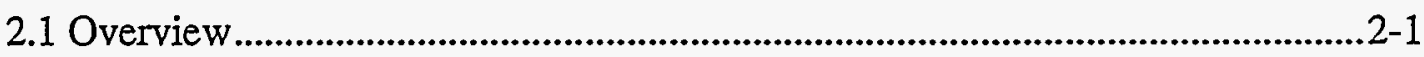

2.2 Fran Ridge Field Experiment................................................................................. 2.1

2.2.1 Limitations of the Data Set ...........................................................................2-3

2.3 Tracer Infiltration at Site A.................................................................................2-5

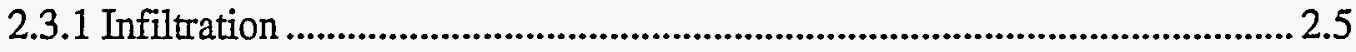

2.3.2 Geophysical Measurements ......................................................................2-7

2.3.3 Qualitative Observation During Disassembly of the Rock Mass ..............2-7

2.3.4 Analysis of Fracture maps Obtained During Disassembly .........................2-9

3. Prioritizing Processes and Material Parameters ...................................................3-1

3.1 Important Processes ..................................................................................... 3-1

3.2 Modeling Approaches for Fractured Media......................................................3-2

3.2.1 Characterization of Heterogęneous Fracture Continuum ............................3-2

3.2.2 Derivation of Hydrologic Properties from Fracture Frequency..................3-4 
3.3 Parameters Influencing Fast-Flow Paths.

3.4 Concept of Equivalent Continuum Model and Dual Permeability Model as used in this Study.

3.5 Effectiveness of Equivalent Continuum and Dual Permeability using OneDimensional Model.

3.5.1 One-Dimensional Problem Description

3.5.2 One-Dimensional Problem Results $.3-8$

3.5.3 Conclusions of One-Dimensional Results.

4. Development of a Block-Scale Model of the Fran Ridge Infiltration Experiment

4.1 Problem Geometry and Material Properties

4.2 TOUGH2 Input File, Material Properties and Initial Conditions. $4-3$

4.3 Numerical Investigations. $4-6$

4.4 Summary of Computational Results $.4-8$

5. Conclusions and Recommendations

5.1 Conclusions $.5-1$

5.2 Recommendations $.5-2$

6. References .6-1

7. RIB Appendix $.7-1$ 


\section{List Of Figures}

Figure 1-1. Sketch of domains for alternative conceptual models of fracture flow......... 1-4

Figure 2-1. Location map of Fran Ridge and surrounding areas. ...................................2-2

Figure 2-2. E-W cross-section through the excavated area at Fran Ridge (not to scale).2-4

Figure 2-3. Plan Map of the test area (not to scale) ..........................................................2-6

Figure 2-4. Cumulative volume of fluid applied following the initial 40 gallon slug; $\mathrm{T} 1$ and $\mathrm{T} 2$ are the two pressure transducers used to measure water levels in the inflow tank. $2-8$

Figure 2-5. Computer enhanced example of pavement map. $2-10$

Figure 2-6.Polar equal-area plot of orientation data for levels 1-11 at Site A.

Only fractures with a measured dip are shown.

Figure 2-7. Histogram of measured fracture trace lengths for levels 1-11 at

Site A. Line reflects exponential fit to all data points except

the shortest fractures which are known to be under-sampled.

Figure 3-1. Fracture map from Fran Ridge site and corresponding fracture

frequency continuum representation. Mapped region is $2.4 \times 2.4 \mathrm{~m} . . . . . . . .3-3$

Figure 3-2. Histogram of fracture frequency distribution, southwest block,

Fran Ridge site.

Figure 3-3. Matrix and fracture elements separated by distances $d_{1}$ and $d_{2} \ldots \ldots \ldots \ldots . . . . . . . .3-6$

Figure 3-4. One-dimensional layered model used in TOUGH2 simulations.

The initial saturation of all the elements was set to 0.85 .

Figure 4-1. Problem Geometry.

Figure 4-2. Top view of computational mesh. $4-2$ 
Figure 4-3 Side view of computational mesh.

Figure 4-4. Top view of computational mesh showing region of ponded source.

Figure 4-5. Geometry used for one-dimensional infiltration investigations.

Figure 4-6. Planes of fracture and matrix saturation at 36 minutes resulting from the dual permeability model (Case1) and equivalent continuum model (Case2). The horizontal planes at $\mathrm{z}=-4.57 \mathrm{~m}$ correspond to the bottom of the heterogeneous core region (not to scale).

Figure 4-7. Planes of fracture and matrix saturations in the core region for Case 1(DK model base case) at 36 minutes.

Figure 4-8. Matrix and fracture saturation along vertical centerline of region, for DK simulations, time $=36$ minutes

Figure 4-9. Saturation distribution along vertical centerline of region for DK model and ECM, time $=36$ minutes.

Figure 4-10. Saturation for the one element and ten element 1-D geometries. 4-14 


\section{List Of TABLes}

Table 4-1. Mean values of properties required for DK model............................................4-4

Table 4-2 Mean values of properties required for the ECM. ............................................4-5

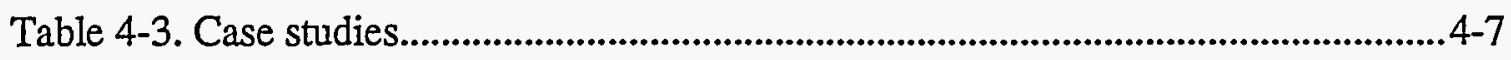

Tables 4-4. Comparison of water distribution using DK and ECM models. .................4-11 


\section{Introduction}

\subsection{Problem Statement}

The geologic strata in the vicinity of a potential high-level nuclear waste repository at Yucca Mountain, Nevada, consists of unsaturated, fractured, variably welded, tuffaceous rock. The highly fractured nature of this domain poses significant challenges for performance-assessment calculations that attempt to predict the flow and transport behavior in this region. First, accurate characterization of the fracture networks is difficult, if not impossible. Important model parameters such as fracture frequencies, apertures, and distributions are therefore scarce and often unreliable. Secondly, some numerical models that have been used in performance-assessment calculations are not even capable of explicitly modeling flow through fractures (Arnold et al., 1995; Wilson et al., 1994; Barnard et al., 1992; Dudley et al., 1988). These composite porosity (equivalent continuum) models are generally used for their computational efficiency, but significant concerns have risen over their ability to model fast-flow paths. The existence of fast-flow paths within the unsaturated fractured rock at Yucca Mountain has been evidenced by several studies including isotopic dating analyses (Fabryka-Martin et al., 1993) and studies of analog sites such as Rainier Mesa (Russel et al., 1987) and Apache Leap (Bassett et al., 1994). Therefore, it is necessary to examine the applicability of continuum-based models and consider possible alternative conceptualizations to ensure that models used for performance-assessment calculations are capturing the salient behavior of unsaturated fracture flow. Since current understanding of flow and transport through the unsaturated fractured rock is far from complete (e.g., Glass and Tidwell, 1991; Glass et al., 1995), decisions between alternative conceptualizations must be based on both process-level understanding and numerical investigation of physical observations at large and intermediate scales. 
This paper focuses on the assessment of two alternative conceptual models (equivalent continuum and dual permeability models) of fracture flow that can be used in performanceassessment calculations. These models are used to simulate a field infiltration tracer test at Fran Ridge in which dyed water was allowed to infiltrate downward into the densely welded, nonlithophysal Topopah Spring tuff (Nicholl and Glass, 1995). This report assesses the capabilities of the models and the importance of several parameters influencing flow through fractured tuff by comparing simulated and observed infiltration fluxes and patterns.

\subsection{Numerical Codes}

Numerical codes used in previous performance-assessment calculations have been limited in their ability to model fast-flow paths through fractured rock (Arnold et al., 1995; Wilson et al., 1994; Barnard et al., 1992; Dudley et al., 1988). Recently, numerical codes have employed alternative models of fracture flow that may better represent the behavior of flow through fractured tuff. One such code, TOUGH2 (Pruess, 1991\&1987), has been recommended by Reeves et al. (1994) for use in Yucca Mountain related calculations and is used in the analyses of this report (versions 3.0 and 3.1 in the SNL software quality assurance configuration management).

TOUGH2 (Transport of Unsaturated Groundwater and Heat) simulates transient, multiphase, non-isothermal flow in one, two, or three dimensions using the integral finite difference numerical method. The fundamental formulation for the governing equations consist of balance laws for mass and energy with Darcy's law for momentum. In the integral finite difference approach, no reference is made to a global coordinate system. Volume elements of arbitrary size and shape are specified by information describing the volume of each element and connection parameters to adjacent elements. Also included in the TOUGH2 code is the MINC (Multiple INteracting Continua) formulation for describing dual porosity and dual permeability systems of fracture flow (Pruess, 1983) as described in Chapter 4. Although the equivalent continuum model is not included in TOUGH2, it has been added to the code following the formulation described in Klavetter and Peters (1986) and Dudley et al. (1988). TOUGH2 incorporates equation-of-state modules (used interchangeably) that govern more specific features of the system such as singlephase flow described by Richards' equation (1931), chemical species transport, and vapor pressure lowering. 


\subsection{Alternative Conceptual Models of Flow in Fractures}

As described above, this report will compare and contrast two alternative conceptualizations for unsaturated flow through fractures, the equivalent continuum model and the dual permeability model. Figure 1.1 shows a sketch of the representative domains of each model, along with a more rigorous discrete fracture model for comparison.

The equivalent continuum model (Klavetter and Peters, 1986; Dudley et al., 1988) has been used extensively in describing flow through fractured rock as a result of its relative simplicity and ease of computational implementation (Arnold et al., 1995; Robey, 1994; Dudley et al., 1988). In this model, the pressures in the matrix and fractures are assumed equal. As a result, the flow through this fracture-matrix system is equivalent to flow through a composite porous medium, which has hydraulic properties comprised of both fractures and matrix properties. Dudley et al. (1988) express that for conditions similar to those found at Yucca Mountain (i.e. low infiltration rates and good coupling between the fracture and matrix), the equivalent continuum model provides a reasonable approximation to fracture-matrix flow. However, recent studies have shown that flow processes such as fingering in fractures (Glass and Tidwell, 1991) and mechanical aspects such as fracture coatings may effectively reduce the coupling between the fractures and matrix. This may cause pressure disequilibrium between the fractures and matrix, even under low infiltration rates.

If pressure equilibrium cannot be assumed, other models such as the dual permeability model must be used (e.g., Pruess and Narasimhan, 1985; Pruess, 1983). Unlike the equivalent continuum model, the dual permeability model represents the fractures and matrix as separate continua. As a result, different pressures can exist in the fractures and matrix, which allows flow to occur between the two continua. Propagation of flow in fractures is more likely to be observed in these models, depending on parameters such as fracture-matrix conductance and capillary pressure gradients between the fractures and matrix. However, relatively few analyses have been performed to date with the dual permeability model in conjunction with analyzing fast flow paths for the assessment of a potential nuclear waste repository.

\subsection{Overview of Report}

The alternative conceptual models described above are used to simulate a tracer experiment performed at Fran Ridge.' As a prelude to these analyses, Chapter 2 summarizes important 


\section{Equivalent Continuum Model}

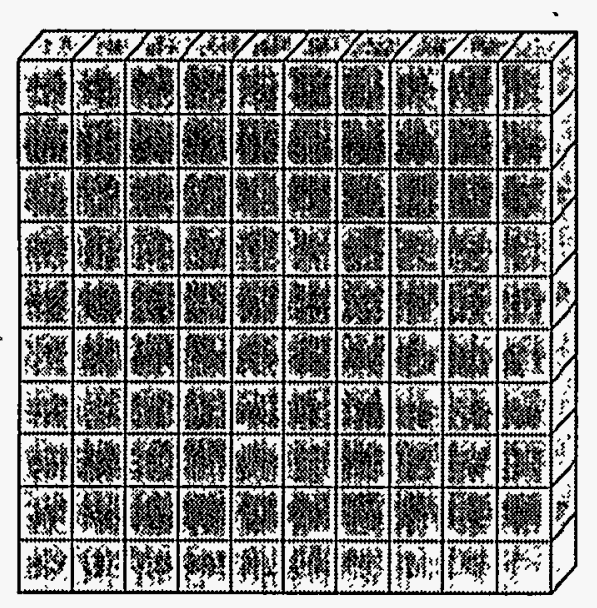

Dual Permealility Model

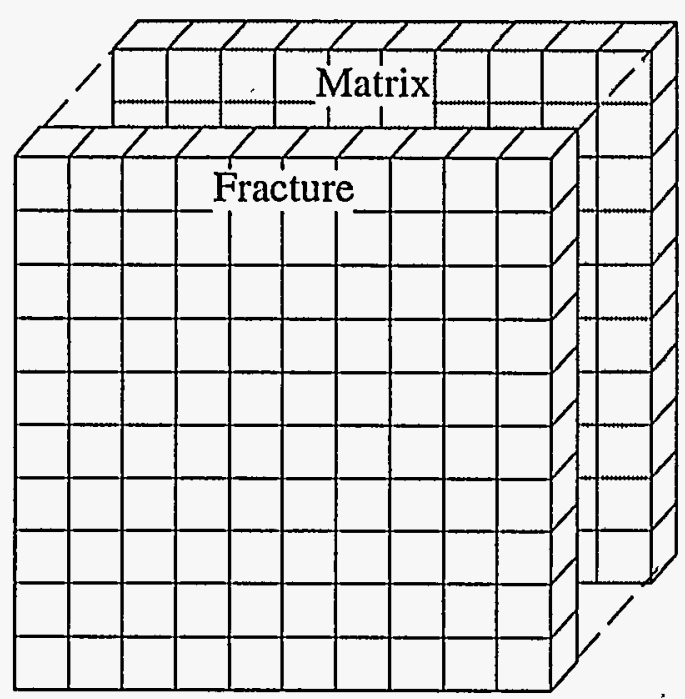

Discrete Fracture Model

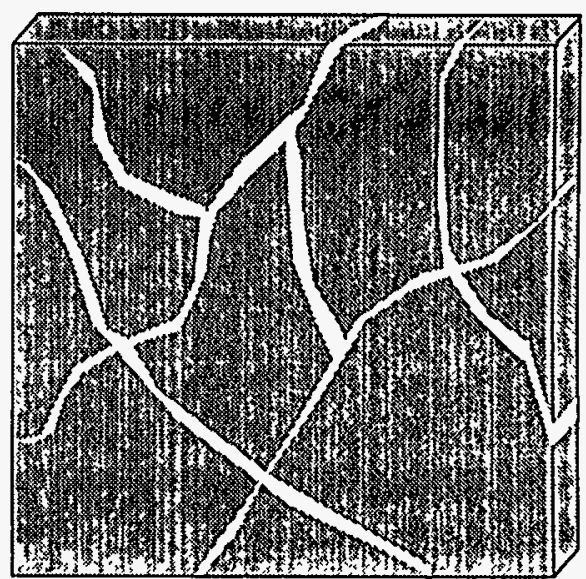

Figure 1-1. Sketch of domains for alternative conceptual models of fracture flow. 
processes and parameters that may influence the observed and predicted flow behavior. Previous studies that are relevant to the analyses of this report are summarized. Chapter 3 presents the details of the tracer experiment performed at Fran Ridge including locations, procedures, and data collection methods. Chapter 4 describes details and results of the numerical modeling efforts. The problem geometry, material properties, and parameter derivation are presented in this chapter. Sensitivity analyses are also presented to investigate fracture-matrix interaction. Comparison between the equivalent continuum and dual permeability models are made and results are discussed. Relevance to performance-assessment calculations and recommendations for future analyses are discussed at the end of the report. 


\section{Chapter \\ Two}

\section{Summary of an Infiltration Tracer Test Performed at Fran Ridge}

\subsection{Overview}

This document describes work directed at discriminating between alternative conceptual models (equivalent continuum and dual permeability) for use in performance-asessment calculations. Rather than use an entirely contrived test problem, it was decided to use a field infiltration test performed at Fran Ridge during the spring and summer of 1994 as a basis for the numerical investigation. In this chapter, we provide a limited description of the Fran Ridge field test; more complete details on the field test will be available in a separate document that is currently under preparation at SNL by Nicholl and Glass (completion expected in FY96).

\subsection{Fran Ridge Field Experiment}

Flow processes in discrete fractures and fracture networks are poorly understood, particularly under unsaturated conditions (see Glass and Tidwell, 1991; Glass et al., 1995). Furthermore, very little data exists regarding the geometry of both individual fractures and 3dimensional fracture networks. For these reasons, researchers from SNL and Lawrence Livermore National Laboratory (LLNL) cooperated to explore a natural fracture system at Fran Ridge (see Figure 2-1) in conjunction with LLNL's Large Block Test (LBT); a large scale investigation of coupled thermo-mechanical, hydrologic, and chemical processes using an intact block from the same formation as that being considered as a potential repository location at Yucca Mountain.

The LLNL large block (Figure 2-2) was prepared by excavating the country rock surrounding an in situ tabular monolith ( 4.5 by 3 by $3 \mathrm{~m}$ ) of densely welded, non-lithophysal, 


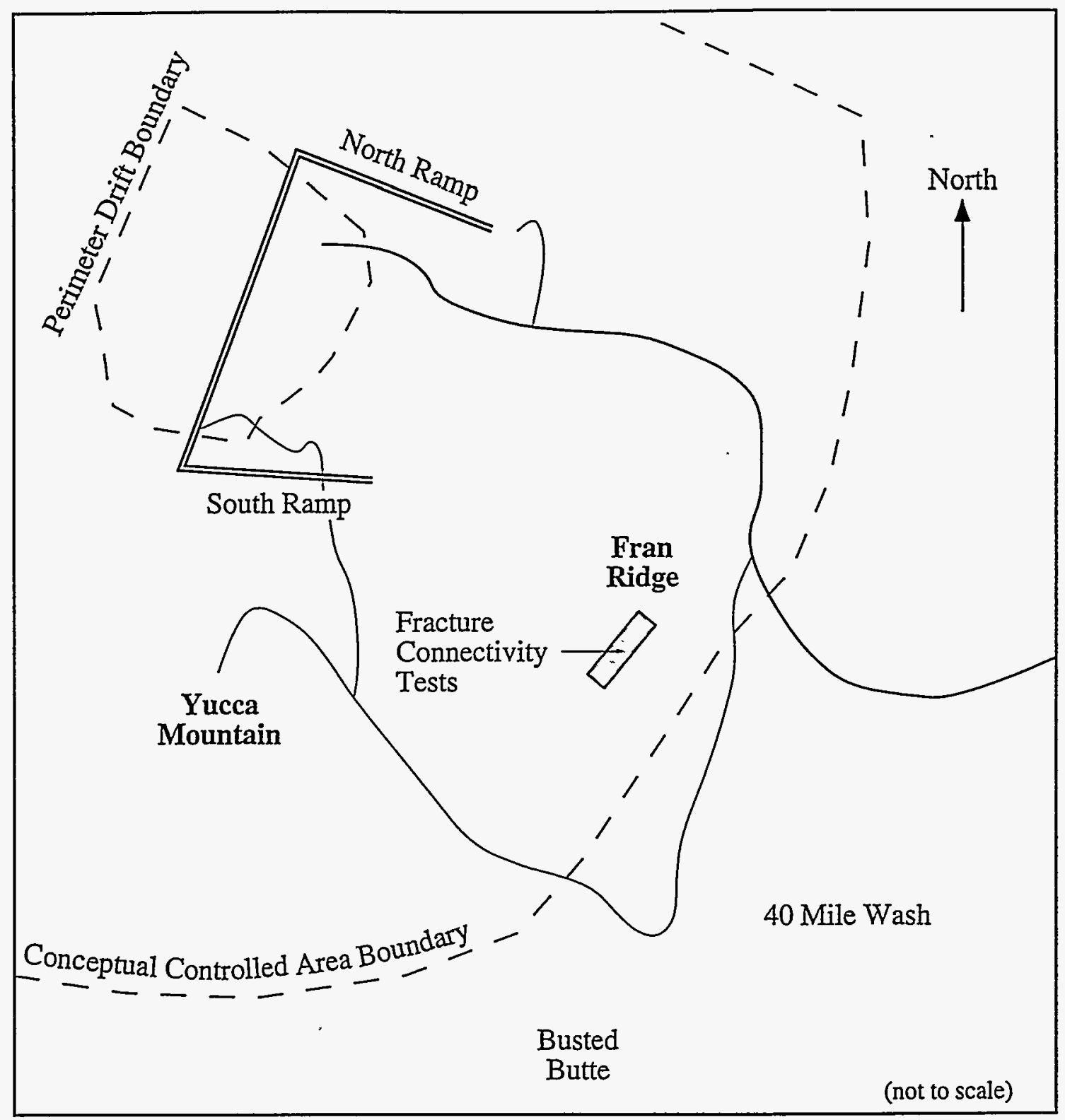

Figure 2-1. Location map of Fran Ridge and surrounding areas (not to scale). 
fractured Topopah Spring Tuff on the eastern side of Fran Ridge. After removing overburden from the region, vertical slots were cut in the rock mass to define the LBT test block and release it from the adjacent country rock. The country rock surrounding the test block was removed in horizontal lifts by using a tracked vehicle (hoe ram) to pulverize the pavement to a depth of approximately 0.5 $\mathrm{m}$; rubble was then removed with a bulldozer. This methodology afforded a unique opportunity to explore the geometry and connectivity of the fracture network, observe small-scale flow processes, obtain samples for hydraulic properties testing, and test the ability of Electromagnetic Resistance Tomography (ERT) to quantify moisture profiles in fractured rock.

The aforementioned objectives were met by introducing fluid containing a visually observable tracer to the fracture network and then mapping the tracer distribution during subsequent excavation. Because the matrix has a very low permeability relative to that of the fractures, the presence of tracer in fractures at depth implies hydraulic connection with the infiltration surface. At each excavated level, regions below the three infiltration pits were cleared using a bulldozer, shovels, and compressed air. An 8 foot $(2.438 \mathrm{~m})$ square mapping grid with grid lines at 1 foot $(0.3048 \mathrm{~m})$ intervals was then placed over pre-drilled vertical locator holes such that the grid lines were oriented along the NS and EW axes and as close to horizontal as practical, considering the locally rough topography. Fracture traces and observed distribution of the tracer were then recorded at a scale of $1^{\prime \prime}=1^{\prime}(0.0254 \mathrm{~m}=0.3048 \mathrm{~m})$ by hand mapping; where possible, fracture dip was also noted. Approximate elevation of the mapped surface relative to a local survey point was determined using a level and stadia rod. Unusual geologic features, ancillary observations, and conditions interfering with mapping procedure were recorded in the accompanying notes. ERT testing (LLNL) was designed (before, during, and after tracer infiltration) with the goal of reconstructing temporal variation in the fracture saturation field through comparison to observed tracer distributions.

\subsubsection{Limitations of the Data Set}

The tracer tests described here were a secondary activity to excavation of the LLNL large block. As a result, the data must be evaluated in light of the limitations imposed by external constraints. In order to minimize impact on excavation operations, the level of detail recorded in the maps was varied in accordance with daily operating conditions. The priorities were set such that extensive fractures were recorded first and smaller features added later. Features smaller than the grid size ( 1 foot $(0.3048 \mathrm{~m})$ ) were often ignored to conserve time. Time constraints also precluded estimation of fracture aperture sizes. The excavation method produced a surface that was often tilted and/or highly irregular. In addition to making the mapping process physically difficult, an irregular surface tends to produce an illusion of reduced fracture connection and increase the 


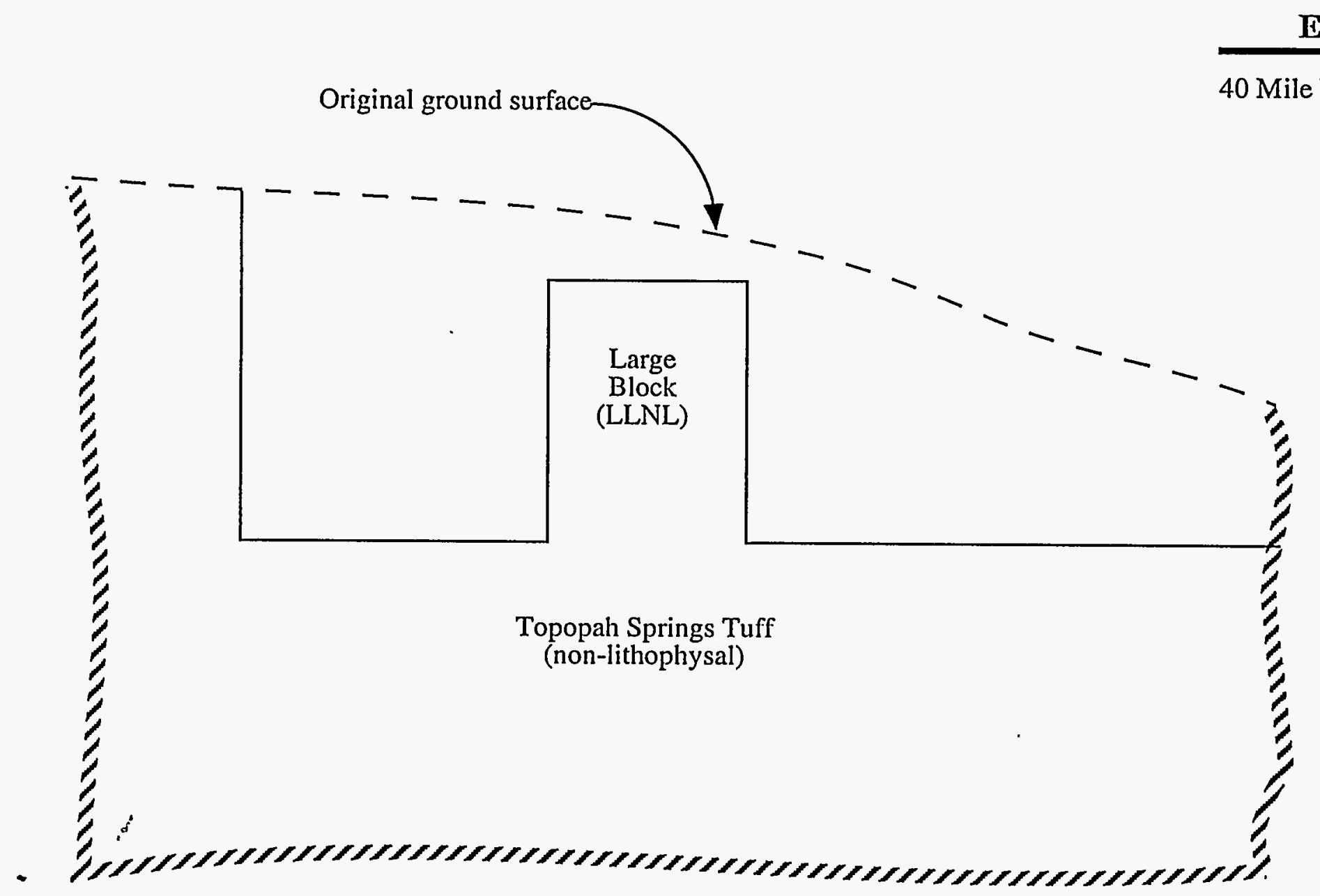

Figure 2-2. E-W cross-section through the excavated area at Fran Ridge (not to scale). 
apparent wandering of non-vertical fractures. However, rough pavements facilitate measurement of fracture dip, which is often difficult to measure on flat surfaces. The concussive nature of the hoe ram also induces local fracturing that can be impossible to differentiate from natural fractures.

There are also other, more general data limitations that must be considered. Geologic mapping is an interpretive art that does not lend itself to exact repeatability. The use of three different geologists on the project undoubtedly introduced interpretive inconsistencies in the mapping activity. The potential for mapping inconsistency was also increased by the intermittent nature ( $\sim$ three times a week) and long time span ( $>5$ months) of the mapping effort. Finally, the nature of the mapping process (sub-horizontal pavements) inherently under-samples low-angle features. This problem was exacerbated by the excavation method, which tended to destroy and obscure sub-horizontal features.

\subsection{Tracer Infiltration at Site A}

Three sites within the excavation surrounding the LLNL block were selected for tracer infiltration (SW, NE, NW corners as shown in Figure 2-3). Site selection was based on maximizing distance from the LLNL block to avoid contamination, minimizing disturbance of the rock mass by previous excavation, selecting surface topography suitable for creation of a surface

reservoir for infiltration, and avoiding near surface caliche deposits. Infiltration sites were prepared for introduction of the tracer fluid by creating a containment pond at the surface. Size and shape of the ponds differed from site to site according to both local topography and experimental requirements.

\subsubsection{Infiltration}

The numerical investigation described in this document is focused on the experiment performed at Site A, which was designed to explore fracture connectivity by flooding the network. The infiltration pond at Site A was located in the SW corner of the excavation (see figure 2-3) at an approximate elevation of $3418 \mathrm{ft}(1042 \mathrm{~m})$. Infiltration (3/11/94) was performed by ponding fluid (J13 well water stained with $\sim 4 \mathrm{~g} / 1$ of FD\&C Blue \#1 food coloring) within the roughly 5 foot (1.5 $\mathrm{m}$ ) diameter pond at a constant level; due to the rough nature of the rock surface, ponding depth ranged from 1 to 6 inches $(2.5$ to $15 \mathrm{~cm}$ ). Ponding was initiated by rapidly applying 40 gallons (151 liters) of fluid using 5 gallon buckets. Elevation of the fluid surface was maintained through gravity feed to a float valve; inflow rate was monitored with a pressure transducer in the feed tank. An additional 165 gallons (625 l) of fluid was applied over the next 36 minutes to make a total 


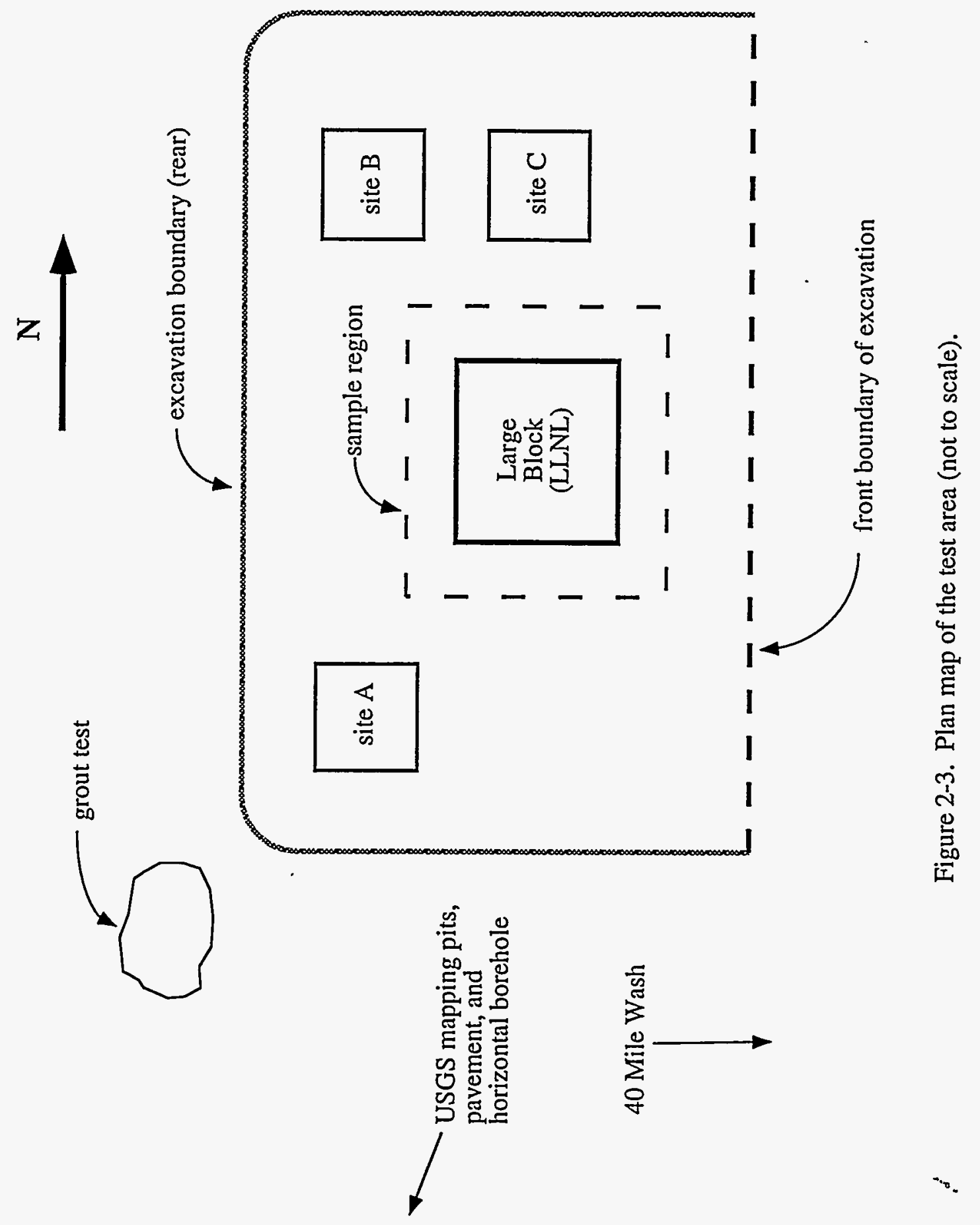


application of 205 gallons (776 1); cumulative infiltration is shown in Figure 2-4. After the fluid supply was exhausted, some water remained on the surface.

\subsubsection{Geophysical Measurements}

In addition to exploring the fracture network and flow processes through flow path visualization, this particular experiment was designed to test the ability of LLNL's Electromagnetic Resistance Tomography (ERT) to delineate 3-dimensional wetting fronts within fractured rock similar to that in the LBT. Prior to infiltration, four 10 foot $(3.1 \mathrm{~m})$ deep holes were dry drilled in the pond for insertion of multi-level ERT probes; 5 surface electrodes were also inserted to a depth of 6 inches $(15 \mathrm{~cm})$. The multi-level probes were aligned to create two perpendicular, crossing planes that were nearly perpendicular to the primary fracture planes, as indicated from surface observations. All holes were subsequently grouted to minimize interference with the infiltration process. ERT data were collected by LLNL personnel before, during, and after infiltration. The infiltration rate at this site was fast with respect to the time required to collect an ERT image, thereby limiting the number of images collected and potentially impacting delineation of the front. Due to changes in project priorities at LLNL, analysis of this data has been limited; preliminary analysis of data collected prior to, during, and the day after infiltration show a resistivity change within the rock mass that passes through the system (i.e., a wetting front).

\subsubsection{Qualitative Observations During Disassembly of the Rock Mass}

In addition to the quantifiable data (infiltration flow rates, fracture and tracer maps), qualitative information was obtained by observing both the infiltration process and disassembly of the rock mass; here we provide a short summary of such observations that are relevant to the numerical experimentation. Shortly after completing infiltration ( $<1$ hour), a heavily stained area of the rock surface was broken in order to assess matric imbibition; no visible evidence of fluid penetration into the matrix was observed. Lack of matrix imbibition is consistent with the rapid nature of this infiltration experiment and extremely low permeability expected in this tight, dense rock. Even though the pavement was not cleared except directly below the infiltration pit, it was possible to obtain a general idea of lateral migration by observing the excavation process. Initially the tracer pulse appeared to go straight down; however, at a depth of several feet it appeared to migrate laterally. It is presumed that lateral migration occurred along sub-horizontal features that appeared to dip with the topography in an easterly direction. Lateral migration appeared to occur in all directions except towards the SW, where a large open fracture may have acted as a capillary barrier. Lateral migration appeared to decline with depth and flow was once again concentrated underneath the infiltration pit. The excavation did not reach the bottom of the dye pulse so the 


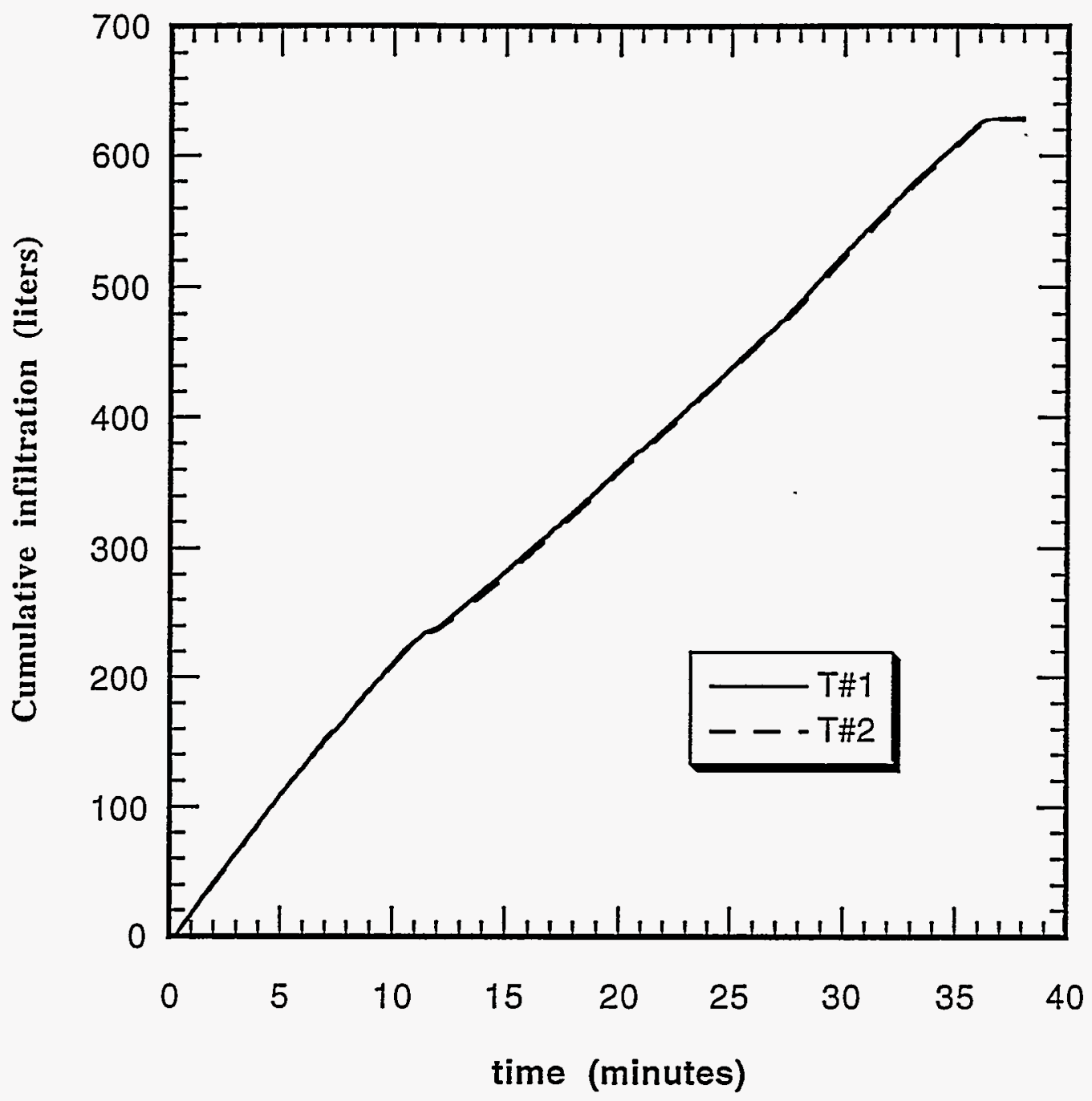

Figure 2-4. Cumulative rate of fluid application following the initial 40 gallon slug; $\mathrm{T} 1$ and $\mathrm{T} 2$ are the two pressure transducers used to measure water levels in the inflow tank. 
depth of penetration of this test is unknown. Finally, some of the rubble showed non-uniform dye stains that implied development of preferential flow structures under unsaturated conditions (i.e., gravity- or capillary-fingering).

\subsubsection{Analysis of Fracture Maps Obtained During Disassembly}

Including the infiltration surface, a total of 12 levels were mapped at Site $A$ over a vertical interval of $\sim 15$ feet $(4.6 \mathrm{~m})$. A digitally enhanced reproduction of a typical map is shown as Figure 2-5. Solid lines reflect observed fracture traces; where available, approximate dip is marked adjacent to the fracture trace. Circles on the fracture trace indicate a significant amount of fracture filling; geochemical composition and genesis of the fracture fill is unknown at this time. Square boxes on the fracture trace indicate a significant change in fracture dip along the plane. Tracer was not observed on fractures outside the thick solid lines, while tracer appeared to be pervasive within. As described above, tracer appears to have migrated outside of the mapped region.

At the infiltration surface, mapping was done after installation of the pond and geophysical arrays, both of which greatly impeded interpretation; therefore, that map (level 0 ) is not used for any quantitative analysis. Subsequent maps (levels 1-11) were analyzed for fracture orientation, trace length, and spatial distribution; only spatial distribution was used in the numerical experimentation. In order to familiarize the reader with the test site, we first summarize the more classical geologic measures, fracture orientation and trace length; extraction of spatial data are described in the following chapter.

Analysis began by assigning numbers to each significant fracture; cross-hatching and subparallel lines drawn to indicate shatter zones were not intended by the mapping geologist to represent individual fractures and were therefore ignored. Complete definition of fracture orientation requires two parameters, dip and dip direction (or alternatively strike). Where possible, dip was collected at the time of mapping to an accuracy of $+1-5$ degrees; dip direction was measured from the maps, and taken as perpendicular to the dominant trace direction in the direction of the dip, if known. As can be seen in the sample pavement map (Figure 2-5), perfectly linear fracture traces were the exception rather than the rule. After considering several alternatives, it was decided that using expert judgment to assign a single dip direction to each fracture would provide the most effective use of the available data. Orientation data for levels $1-11$ is displayed by plotting poles of the fracture planes on a polar equal-area stereographic projection (Figure 2-6); data is subdivided into 4 groups on the basis of measured trace length. Most of the measured fractures exhibit near vertical dips; however, as discussed above, this observation must be considered in light of the fact that horizontal pavements preferentially sample steep fractures. The less extensive 


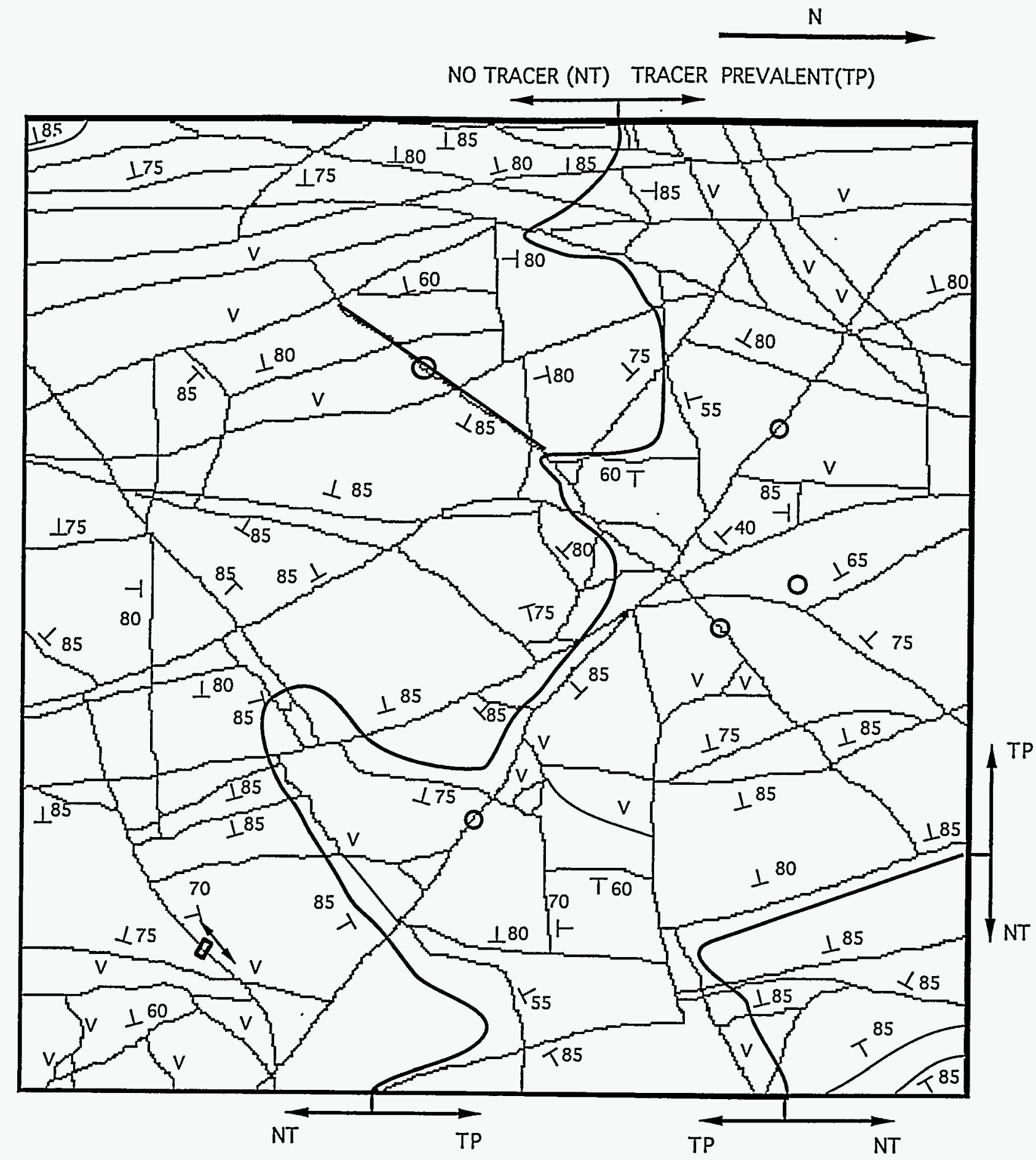

Figure 2-5. Computer enhanced example of a pavement map. Extemal dimension of the mapped area is 8 feet $(2.438 \mathrm{~m})$. Data was collected on $8 / 2 / 94,-15$ feet $(4.57 \mathrm{~m})$ below the infiltration surface at Site $A$. The following symbols are used in the map: $v=$ vertical dip; $O=$ filled fracture; $\square=$ significant dip change. 


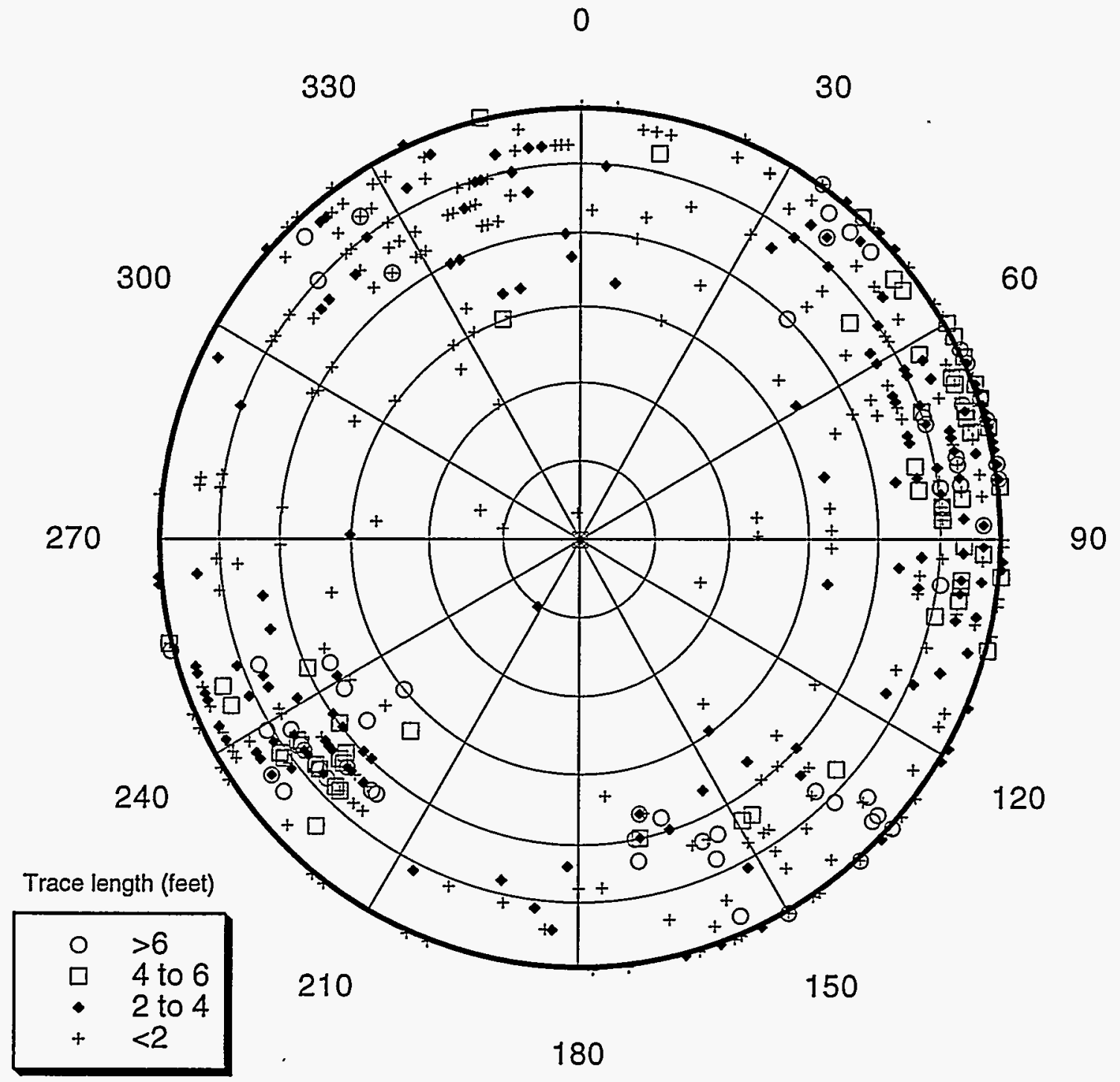

Figure 2-6. Polar equal-area plot of orientation data for levels 1-11 at Site A. Only fractures with a measured dip area shown. 
fractures exhibit a greater variation in both dip and strike than the more extensive features, which appear to cluster in 2-4 primary sets; a more complete analysis of fracture orientation is currently under preparation at SNL by Nicholl and Glass.

The length of each numbered fracture was determined using a mechanical map measure. Not all fractures mapped were assigned a dip; therefore, it was decided not to correct trace length for dip. Because most of the measured dips were near vertical and the same can reasonably be assumed for those not measured, error in estimating trace length introduced by neglecting the dip will be minimal. Due to constraints placed on mapping activities, the trace length data (Figure 2-7) must be interpreted with caution. Fractures smaller than 1 foot $(30.5 \mathrm{~cm})$ in length were undersampled during mapping due to both time constraints and difficulty discerning between natural and excavation induced features. A second concern is associated with censoring of fracture traces. As the mapped area was of limited spatial extent ( 8 foot $(2.438 \mathrm{~m})$ grid), many fractures extended outside the boundaries of the mapped region. Because that area was excluded from observation (rubble covered or not excavated), it was impossible to determine the exact length of such features. This censoring of the data accounts for the hump in Figure 2-7 at 8 feet $(2.438 \mathrm{~m})$, an arbitrary length scale imposed by the mapping grid. The exponential fit shown in Figure 2-7 ignores the under-sampled data ( $<1$ foot $(0.3048)$ ), but does not account for censoring and hence must be viewed with caution. 


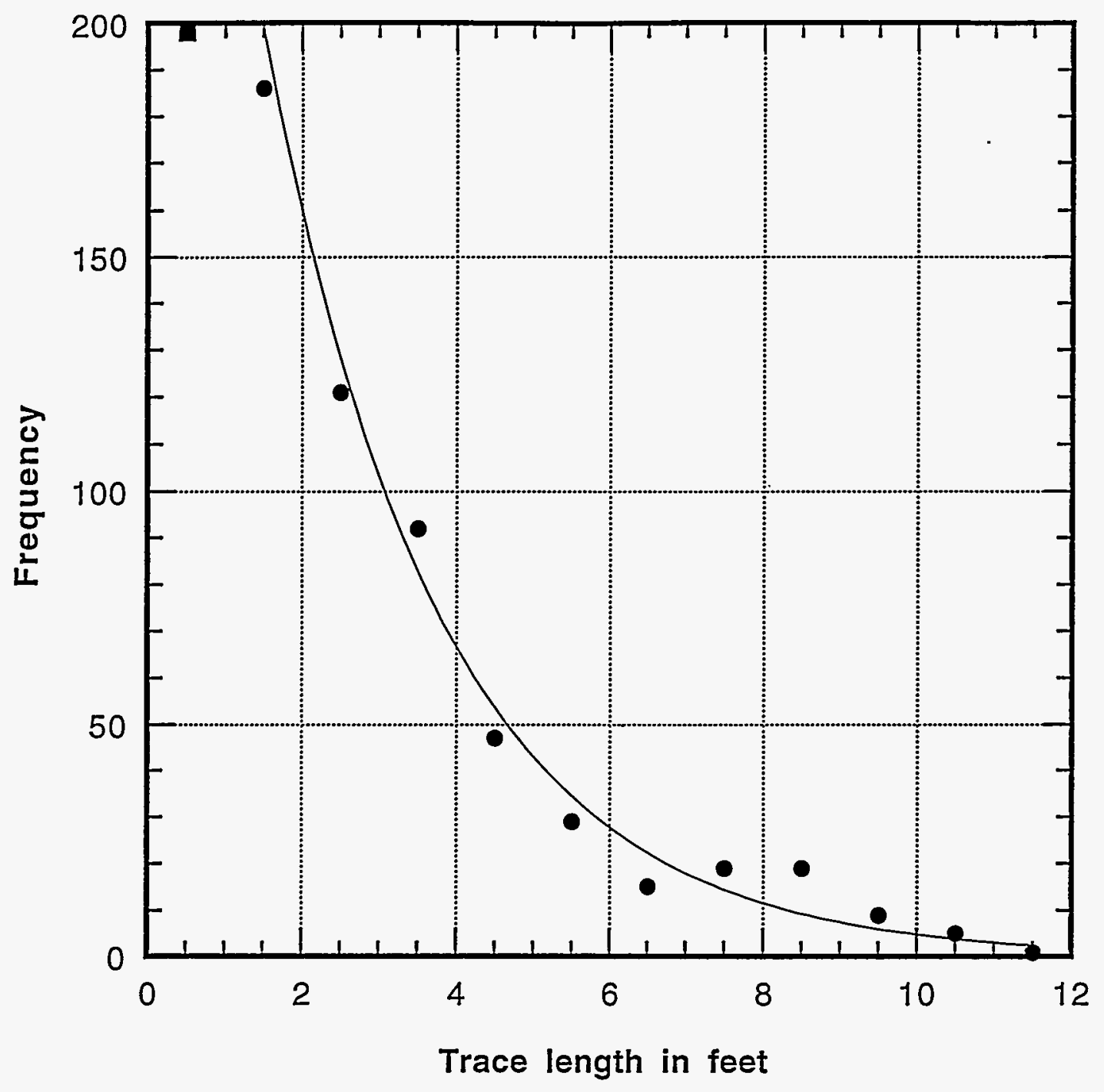

Figure 2-7. Histogram of measured fracture trace lengths for levels 1-11 at Site A. Line reflects exponential fit to all data points except the shortest fractures which are known to be under-sampled. 


\section{Chapter \\ THREE}

\section{Prioritizing Processes and Material Parameters}

\subsection{Important Processes}

A significant amount of work has been done to develop analytical and computational models that incorporate the salient features of water flow in nonhomogeneous media. Due to the diversity of the spatial scales (meters to kilometers) and time scales (minutes to tens of thousands of years) there still exist many questions regarding the reality of these models. The applicability of current formulations such as the equivalent continuum model (ECM) (Peters and Klavetter, 1988) and the dual permeability model (DK) (Pruess, 1983) were recently challenged by Glass and Tidwell (1995). In their paper they provide examples of how recent advances in understanding of small-scale processes in single fractures may influence the behavior of fluid flow in fracture networks and ensembles of matrix blocks sufficiently to impact the formulation of intermediate-scale effective media properties. Some of the processes included in their discussion are gravity-driven fingering, hysteretic fracture response, and barrier/confluence mechanisms. They also explore, by means of a thought experiment, how these same small-scale processes could couple to produce a largescale system response thought to be inconsistent with some current conceptual models of flow through unsaturated, fracture rock.

The example that is often cited is the development of significant flow through a few isolated fractures as is often observed in mine drifts (Bassett et al., 1994, Russel et al. 1987). Glass and Tidwell 1995, suggest that limited inter-block contact area within fractures may contribute to this type of flow channeling. An equivalent permeability

$\because$. coupling the fractures and matrix in the DK conceptualizaton would be a strong function of the contact area which in turn is directly related to local saturation.

- Procedures for efficiently incorporating these submeter and meter-scale features into a large scale problem are still being studied. The ECM, which is often used in repository 
studies, does not model this preferential fracture flow situation without inclusion of significant small-scale heterogeneities such as permeability variations. This effect, to some extent, is incorporated into the DK model by defining separate numerical arrays to model the fractures and matrix. The numerical calculations presented in this report apply both the ECM and the DK to a field experiment at Fran Ridge in an effort to gain a better understanding of how to model fracture dominated flow in unsaturated rock.

\subsection{Modeling Approaches for Fractured Media}

There are three primary approaches to the representation of fractured media in groundwater flow modeling. In the first, a network of fractures may be represented as a homogeneous continuum in which the hydraulic properties of the fracture network are embodied in a single set of "average" hydrologic parameters. This approach assumes that the representative elementary volume (REV) of the fracture network is much smaller than the scale of interest and that the fracture domain can thus be represented as a homogeneous porous medium. In the second method, the discrete fracture approach, individual fractures in the fracture network are explicitly included in the representation of the fractured medium. Typically the discrete fracture approach necessitates a complex representation of the fracture network and requires detailed knowledge of fracture network characteristics. Additionally, the discrete fracture approach can be used to model a subset of important fractures or faults. The third approach characterizes the fractured medium as a stochastic continuum, in which heterogeneous equivalent permeability is a spatially varying parameter for which spatial conductivity is defined in geostatistical terms (Neuman, 1987). When exhaustive information on the fracture network is available, a deterministic, heterogeneous continuum representation of the fracture network can be used in modeling. In most cases exhaustive information on the fracture network is not available and the modeler must resort to using a geostatistical description of the fracture properties and geostatistical simulation techniques to characterize the system. The modeling presented here uses the heterogeneous continuum approach to model the fracture pattern mapped at the Fran Ridge site. Specifically, the DK and the ECM models are used.

\subsubsection{Characterization of Heterogeneous Fracture Continuum}

A deterministic, heterogeneous continuum approach was used in this work to model the fracture pattern mapped at the Fran Ridge Site, based on the distribution of fracture 
frequency on mapped surfaces. It was assumed that there exists a correlation between fracture frequency and connectivity which is known to be a strong function of the block scale permeability. The fracture frequency within each $0.3 \times 0.3 \mathrm{~m}$ block was calculated by dividing the total length of fracture traces within the block by the area of the block. $A$ majority of the fractures were near vertical and no correction to the calculated frequency was included to account for the angle between the fractures and the plane of observation. A comparison between the fracture map and the corresponding fracture frequency field at the $1038 \mathrm{~m}$ elevation is illustrated in Figure 3-1. This analysis was completed for each of the ten mapped layers.
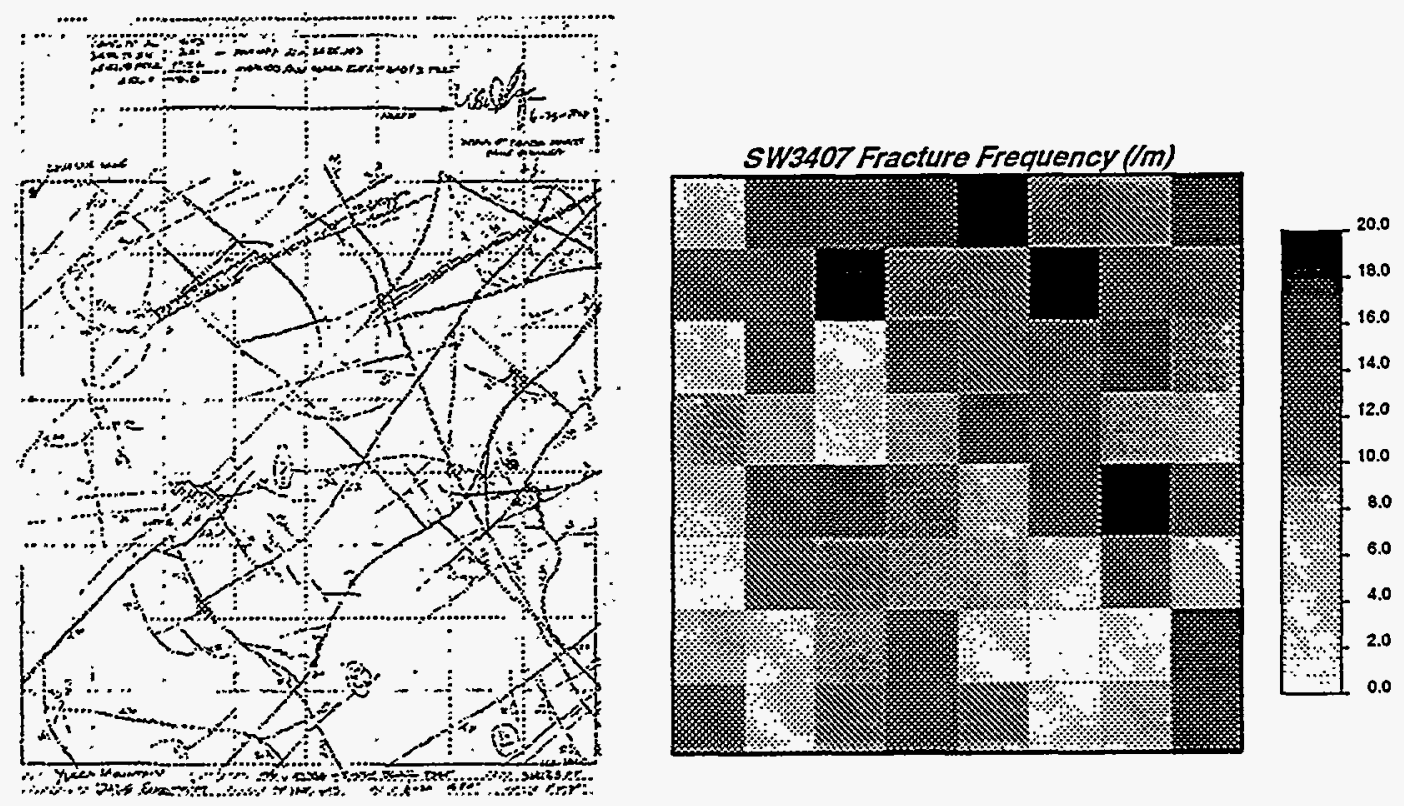

Figure 3.1. Fracture map from Fran Ridge site and corresponding fracture frequency continuum representation. Mapped region is $2.4 \mathrm{~m} \times 2.4 \mathrm{~m}$.

Examination of plots of fracture frequency for all ten layers reveals that the fracture frequency is somewhat higher in the western part of the area. This variation indicates that the spatial distribution of fracture frequency may be statistically nonstationary across the mapped area. The statistical distribution of fracture frequency for the ten layers is summarized in Figure 3-2. The distribution is roughly normal with a mean fracture frequency of approximately $9.1 \mathrm{~m}^{-1}$. This global average fracture frequency at the Fran Ridge site is significantly higher than the expected value of $3.0 \mathrm{~m}^{-1}$ for the Topopah Spring welded unit reported in TSPA-93 (Wilson et al., 1994). In part, the higher fracture frequency at Fran Ridge may be due to fracturing by unloading near the topographic surface. Another important consideration in comparing fracture frequency observations by 
pavement mapping (as at Fran Ridge) to borehole or core mapping (as for TSPA-93) is the bias associated with the orientation of observation. Fracture pavement mapping is biased toward vertical fractures and borehole observations are biased toward horizontal fractures. Corrections have been applied to borehole data to account for fracture dip, but it is not clear that the bias has been eliminated. It is also possible that the Fran Ridge site is located in a region of anomalously high fracture density.

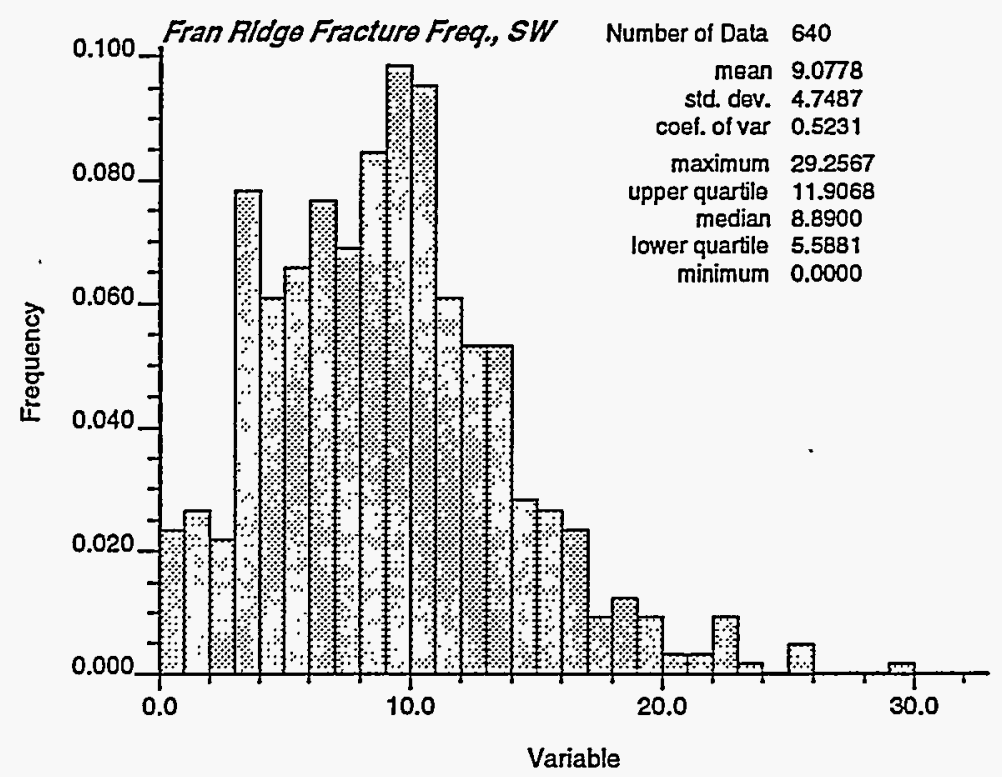

Figure 3-2. Histogram of fracture frequency distribution, southwest block, Fran Ridge site.

\subsubsection{Derivation of Hydrologic Properties from Fracture Frequency}

The deterministic continuum representation of fracture frequency presented above must be converted to a heterogeneous distribution of hydrologic properties for numerical modeling of fluid flow. By assuming constant fracture aperture, the fracture bulk permeability and fracture porosity can be calculated for each $0.3 \mathrm{~m} \times 0.3 \mathrm{~m} \times 0.46 \mathrm{~m}$ block (see Table 4-1 for relationships and Section 4.2 for a discussion of the limitations of assuming permeability as a function of fracture frequency). In addition, for the DK model the fracture-matrix distance and fracture-matrix connection area are calculated based on fracture frequency. The fracture-matrix interaction parameters are based on a continuum representation in which orthogonal fractures divide the matrix into equal dimensional blocks.

The assumption of constant fracture aperture has important implications for the validity of the deterministic continuum representation of the fracture network presented here. If 
fracture aperture is constant, the fracture permeability field is directly proportional to the fracture frequency field. If, however, there is significant variability in fracture aperture, the permeability field may have little correspondence to the fracture frequency field, due to the cubic relationship between fracture permeability and fracture aperture. Because the distribution of fracture aperture in the fracture network is not known and cannot be accurately measured on the scale of this study, the validity of assuming constant aperture remains unresolved.

\subsection{Parameters Influencing Fast-Flow Paths}

Large portions of the geologic media at Yucca Mountain are extremely nonhomogeneous. These heterogeneities can typically be divided into three scales: subrepository, repository, and mountain scale. Heterogeneities result from material property variations, fracture variations, and geologic unit boundaries. Some heterogeneities focus the flow of water within the mountain as a result of channeling and capillary barriers. It was demonstrated by Dykhuizen and Eaton (1991) using numerical exercises, that certain mixes of binary materials tend to channel water flow. Other studies show that differences in material properties at geologic unit boundaries might create differences in suction pressures, which can result in a significant amount of lateral flow (Prindle and Hopkins, 1990). Such heterogeneities can combine with flow processes to form fast-flow paths for water particles migrating through the mountain.

The validity of numerical models used to analyze these various forms of heterogeneities is being studied in order to gain a better understanding of which models provide the most appropriate abstraction of the physical system. The numerical investigations presented here focus on the use of the ECM (Peters and Klavetter, 1988) and the DK model (Pruess, 1983).

\subsection{Concept of the Equivalent Continuum Model and the Dual Permeability Model as Used in This Study}

The fundamental assumption used in the equivalent continuum model is pressure equilibrium between the fractyres and the matrix. As a consequence, the saturation, 
permeability, and porosity can be defined using the following functions (Peters and Klavetter, 1988):

$$
\begin{gathered}
s_{b}=\frac{s_{f} \phi_{f}+s_{m}\left(1-\phi_{f}\right)}{\phi_{f}+\left(1-\phi_{f}\right) \phi_{m}}, \\
K_{b}=K_{m}\left(1-\phi_{f}\right)+K_{f} \phi_{f}, \text { and } \\
\phi_{b}=\phi_{m}\left(1-\phi_{f}\right)+\phi_{f} .
\end{gathered}
$$

where: $s_{b}=$ bulk saturation, $s_{f}=$ fracture saturation, $s_{m}=$ matrix saturation, $\phi_{\hat{\mathrm{f}}}=$ fracture saturation, $\phi_{m}=$ matrix saturation, $K_{b}=$ bulk conductivity, and $K_{m}=$ matrix conductivity .

The pressure equilibrium assumption reduces the complexity of the flow calculation since it requires the solution of only one mass flow equation to obtain the flow in the fractures and matrix. A single element represents a composite of both the matrix and fracture materials. However, as discussed by Peters and Klavetter (1988) this assumption severally limits its applicability to transient flows with significant fracture flow, such as the case in the Fran Ridge infiltration experiment.

In the dual-permeability model, pressure equilibrium is not assumed. Separate fracture and matrix elements are required, which at least doubles the number of elements needed for a given problem compared to that required when using the ECM. The separation distances (d) between the fracture elements and matrix elements is illustrated in Figure 3-3. It is anticipated that the DK formulation is more applicable for transient problems such as the Fran Ridge experiment where pressure equilibrium is not likely to be a valid assumption.

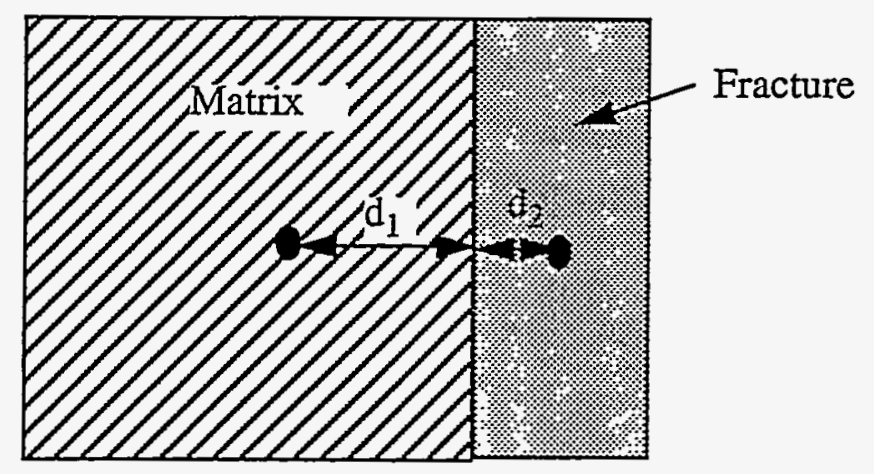

Figure 3-3. Matrix and fracture element separated by distances $d_{1}$ and $d_{2}$. 


\subsection{Effectiveness of Equivalent Continuum and Dual Permeability Using a One-Dimensional Model}

A comprehensive assessment of the ECM and DK models was given by Ho (1995). A summary of his work will be given here. In order to compare these two models, infiltration into a hypothetical one-dimensional vertical transect of Yucca Mountain was investigated.

\subsubsection{One-Dimensional Problem Description}

The domain was modeled using TOUGH2 (1991). A saturated boundary condition was assumed at the bottom, and a constant infiltration rate was assumed at the top boundary. In the ECM, 106 elements were used as shown in Figure 3-4. In the DK model, an additional set of 106 elements to represent the fractures was created using MINC (Pruess, 1983). As a result, twice as many elements were used in the DK model. In addition, the constant infiltration rate was applied only to the top of the fracture continuum in the DK model. The material properties that were used for both models were taken from TSPA-93 (Wilson et al., 1994) and are summarized by Ho (1995). The van Genuchten (1980) capillary pressure and relative permeability curves were used for all calculations, and the initial saturation of all domain elements was set to 0.85 . Isothermal conditions were assumed to exist, and the single-phase EOS9 module (Richard's equation) of TOUGH2 (v.3.1 SNL Configuration Management) was used.

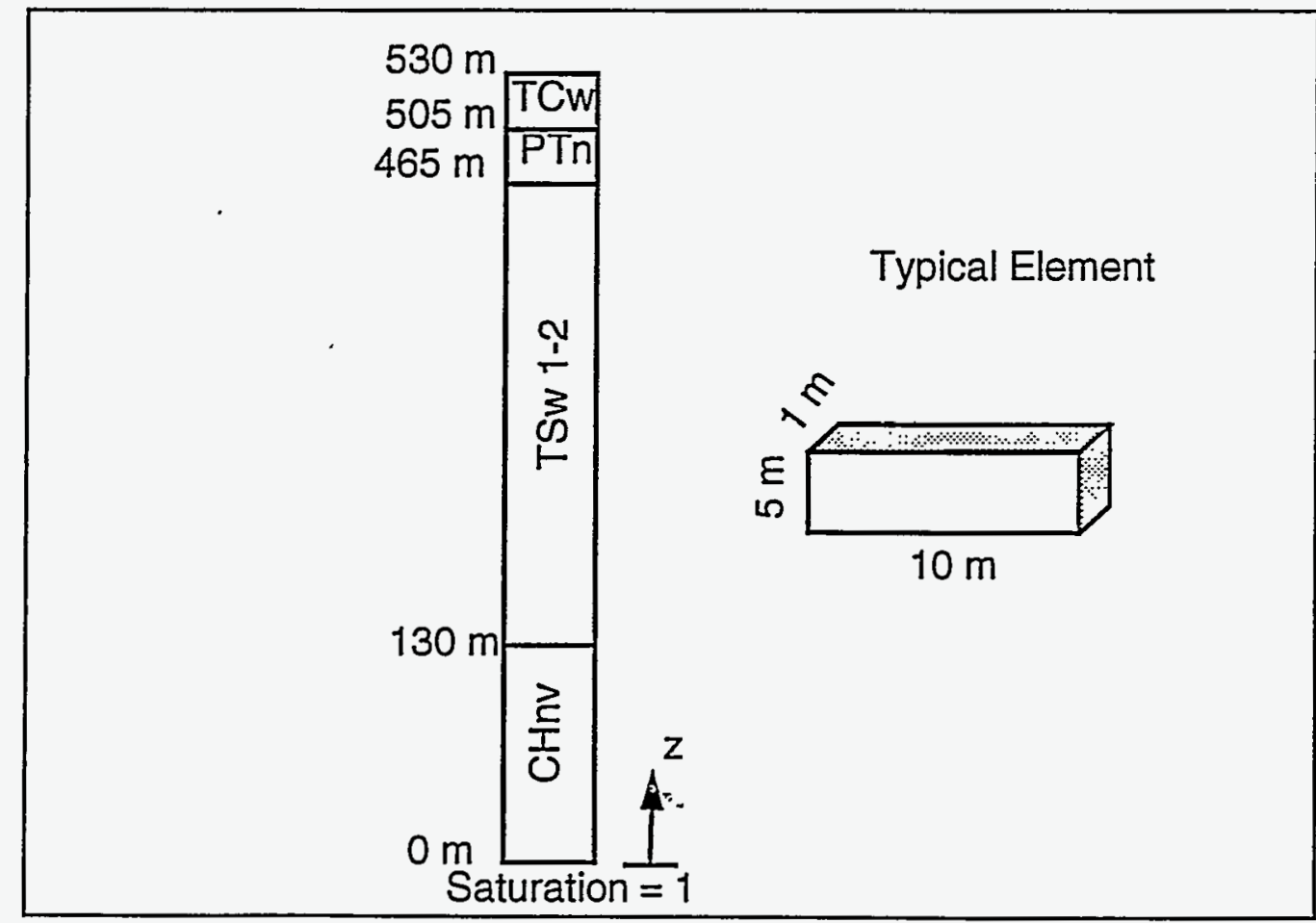

Figure 3-4. One-dimensional layered model úsed in TOUGH2 simulations. The initial saturation of all the elements was set to 0.85 . 
Parameters such as the fracture-matrix connection areas and the distances between the fratures and matrix centroids that were used in the DK model were calculated in MINC, part of the TOUGH 2 code. To execute a sensitivity analysis, the connection areas between the fracture and matrix elements were reduced by two orders of magnitude from the MINCcalculated values in some of the DK simulations. Such a reduction is reasonable with respect to the findings of laboratory experiments summarized by Glass and Tidwell 1995.

\subsubsection{One-Dimensional Problem Results}

The ECM and DK models were seen to produce similar results when the conductance between the fractures and matrix was sufficiently large. In this case equilibrium pressure between the fractures and matrix is required. This is the basic assumption in the formulation of the ECM. Because the MINC calculations were based on idealized geometric configurations of fracture and matrix blocks (full surface contact), the calculated conductances were large. When this conductance was reduced by two orders of magnitude, the DK model showed significant differences in the fracture and matrix velocities even at steady state.

\subsubsection{Conclusions of One-Dimensional Results}

Infiltration into a one-dimensional, layered, unsaturated domain was investigated using ECM and DK formulations. Two different infiltration rates $(0.1 \mathrm{~mm} / \mathrm{yr}$ and $4.0 \mathrm{~mm} / \mathrm{yr})$ were used. Based on the results of these simulations, Ho (1995) reached the following conclusions:

- The MINC-calculated DK model (based on an ideal fracture-matrix geometry) produced similar results to those of the ECM for both infiltration rates under steadystate conditions. For the $0.1 \mathrm{~mm} / \mathrm{yr}$ infiltration rate, the matrix was able to carry the entire flow. The $4.0 \mathrm{~mm} / \mathrm{yr}$ infiltration rate was greater than the saturated conductivity of the welded units, which resulted in significant fracture flow in those regions.

- Reducing the conductance by two orders of magnitude between the fractures and matrix in the DK model resulted in significantly higher fracture pore velocities where the matrix was unsaturated. Thus, depending on the fracture-matrix conductance, the DK model is capable of modeling significant fracture water propagation even when the matrix is unsaturated.

-The steady-state saturations and velocity profiles in the DK model are sensitive to the 
fracture-matrix interaction. The fracture-matrix interaction depends on both the conductance terms between the fractures and matrix (e.g., the fracture-matrix connection area) and the capillary pressure gradient (which, in this study, was affected by the infiltration rates).

- The effective area (conductance) between fractures and matrix needs to be quantified and assessed through laboratory or field studies to provide reasonable estimates for use with the DK model.

These results are for a one-dimensional model. Application of the same methodology will be presented for the simulation of three-dimensional Fran Ridge experiment. It is anticipated that the results obtained using the ECM and DK models to simulate the experiments will show larger differences as a result of the nonequilibrium pressure conditions at early experimental times ( $t>36 \mathrm{~min}$.). 


\section{Chapter \\ Four}

\section{Development of a Block Scale Model of the Fran Ridge Infiltration Experiment}

\subsection{Problem Geometry and Material Properties}

An $2.4 \mathrm{~m} \times 2.4 \mathrm{~m} \times 4.6 \mathrm{~m}$ core region of Fran Ridge has been extensively mapped for fracture frequencies using a $0.3 \times 0.3 \mathrm{~m}$ horizontal grid at $\sim 0.46 \mathrm{~m}$ vertical intervals (Nicholl and Glass, 1995). The resulting 640 frequencies have been used in the formulation of the computational region, as outlined below. To numerically isolate the nonhomogeneous core region from the applied noflow boundary conditions, the core region is embedded in an $8.4 \times 8.4 \times 79.6 \mathrm{~m}$ buffer region, Figure 4- 1 . The numerical discretization of the total model region is given in Figures 4-2 and 4-3.

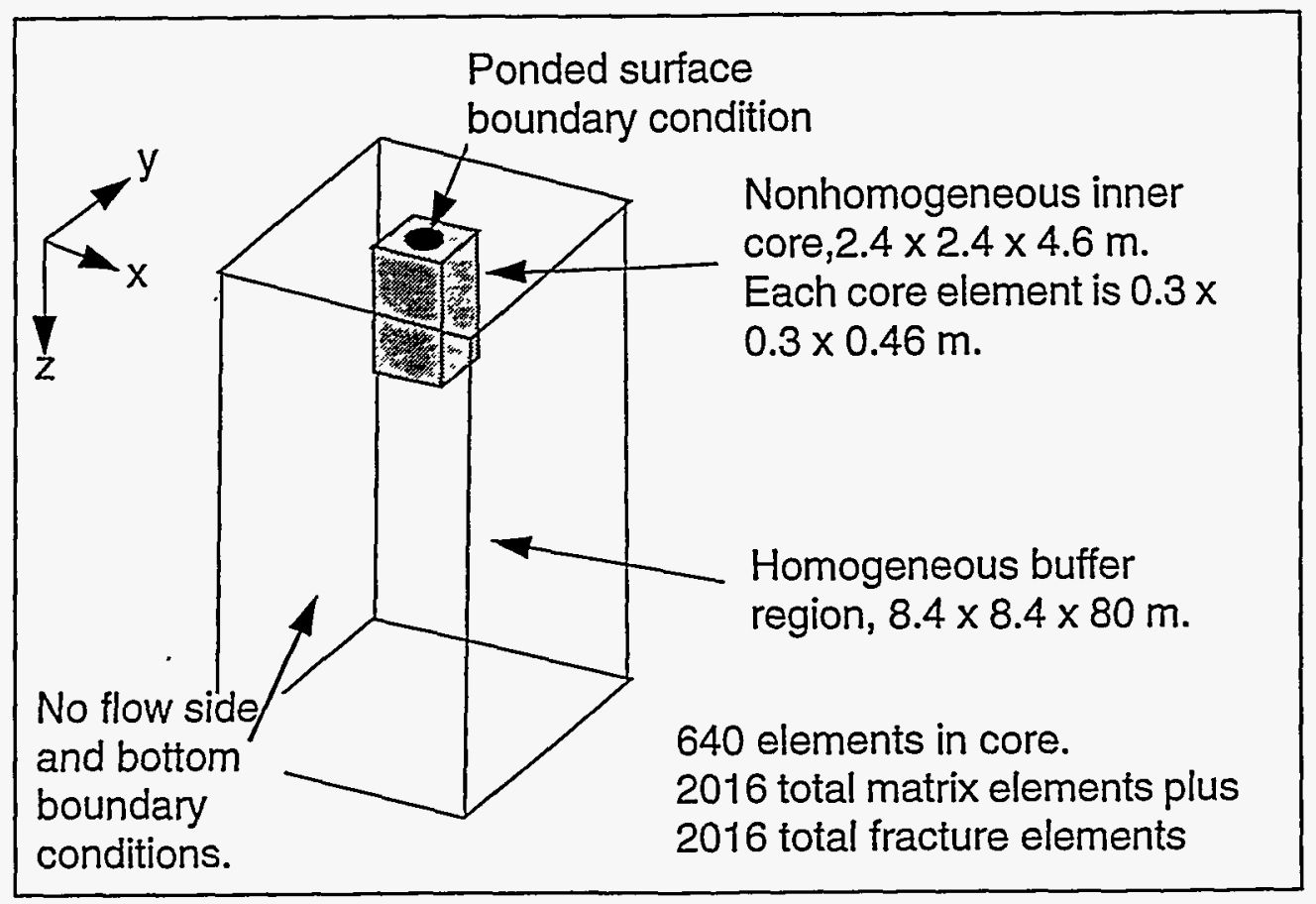

Figure 4-1. Problem geometry. 


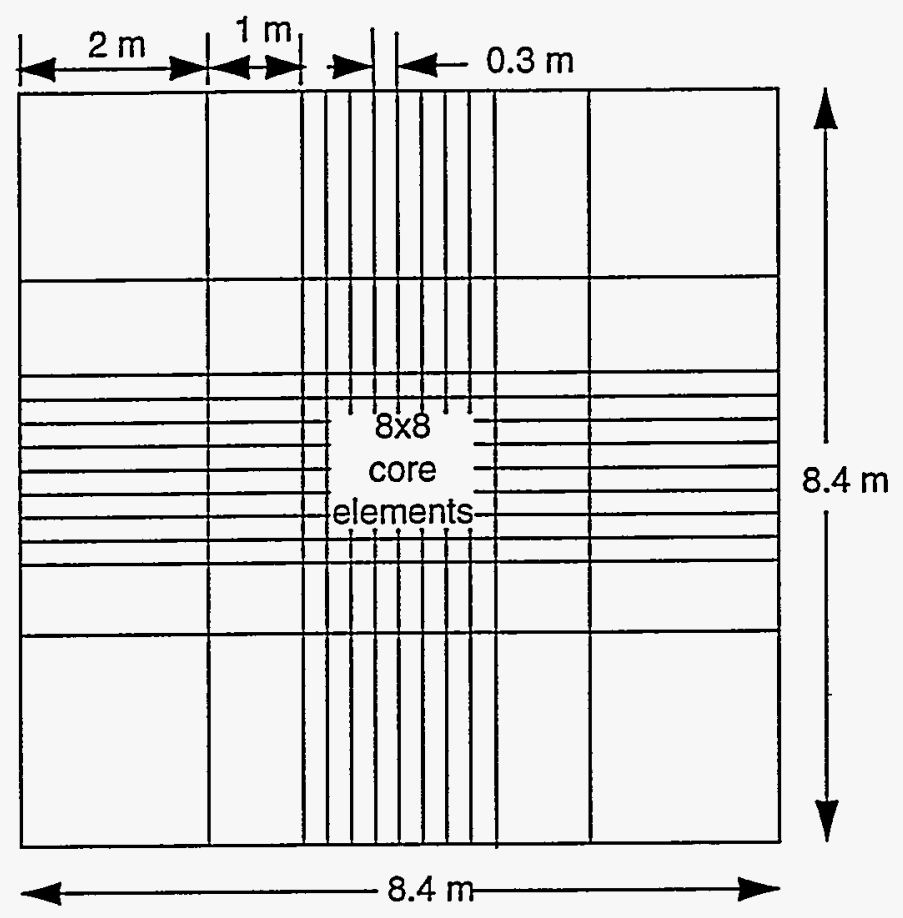

Figure 4-2. Top view of computational mesh.
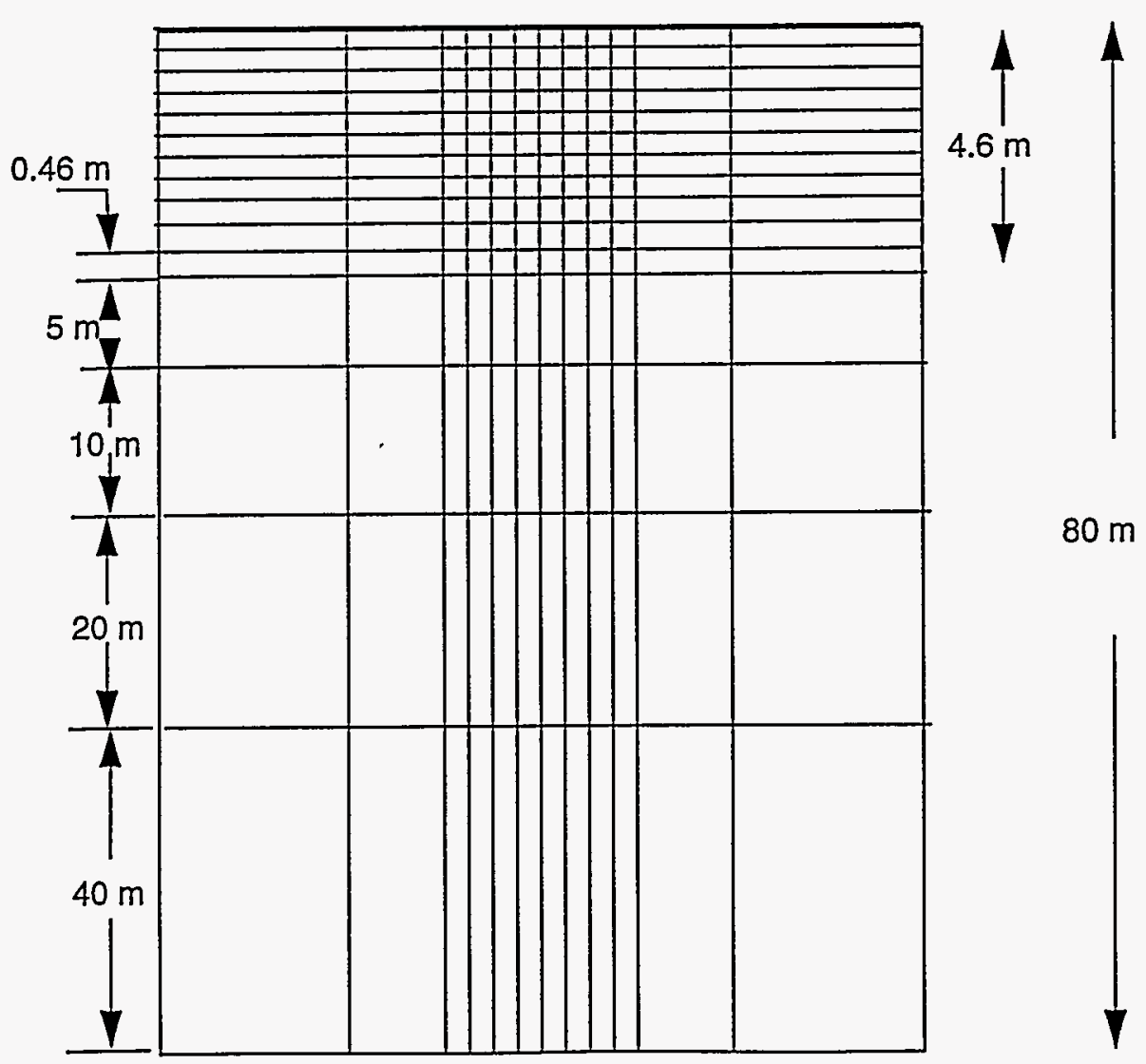

Figure 4-3. Side view of computational mesh. 
The buffer region is assigned a single set of material properties that represent the average of those experimentally recorded in the core region. The mapped fracture frequencies were used to generate spatially variable properties for each of the 640 inner core elements. Properties such as permeabilities, porosities, and fracture/matrix connection areas were calculated for the DK model as outlined in Table 4-1. Properties used in the ECM are given in Table 4-2. The TOUGH2 input file for this problem is quite large

\subsection{TOUGH2 Input File, Material Properties and Initial Conditions}

The generation of a TOUGH2 input file to simulate the Fran Ridge experiment is complicated by the 640 nonhomogeneous core elements which required data statements to identify material properties, element geometry and initial conditions for each element. The resulting input data file is 29000 lines in length. The input was generated using the MESHMAKER and MINC options of TOUGH2 as described in the users manual (Karsten, 1987).

The material properties used as input to the calculations were a mix of properties dervived from experimentally measured values of fracture frequencies and material properties given in the TSPA (Wilson et al. 1993) for the TSw2 unit. A summary of these values are given in Tables 4-1 and 4.2. The procedure for measuring the fracture frequencies are discussed in sections 2.0 and 3.2. The number of fractures per element block ranged from zero to over 20 .

Many of the required material properties for TOUGH2 are assumed to be functions of fracture frequency. It is realized that fracture frequency and fracture permeability are not necessarily strongly related. The permeability is often a direct function of fracture connectivity and not fracture frequency, since unconnected fractures tend to flow small amounts of water if they are not connected. On the other hand, a few well connected fractures may have the capability to transport an appreciable amount of water. However, since the experimental data directly available for this study is fracture frequency and not connectivity it will be assumed that there is some correlation between fracture frequency and material properties. The relationships between fracture frequency and many of the material properties are shown in Table 4-1. For example, the permeabilities for each of the 
core elements are based on Poiseuille flow between flat plates and the fracture frequencies obtained from the excavation of the field site.

$$
K_{s f}=\frac{b^{3}}{12 D}
$$

Where: $K_{s f}=$ saturated fracture permeability, $b=$ fracture aperture, and $D=$ the distance between fractures. Other properties that depend on fracture frequency such as fracture porosity, fracture volume in each grid block, matrix volume in each grid block, optimum distance between fractures and adjoining matrix, and connection area between matrix and fractures are given in Tables 4-1 and 4-2.

The material properties in the core region were based on the experimentally mapped fracture frequencies as discussed above. The properties for the elements lying in the buffer regions were calculated using the same equations and the mean of the frequencies in the core region, $9.1 \mathrm{~m}^{-1}$.

Table 4-1: Mean values of properties required for the DK model.

\begin{tabular}{ll}
\hline Permeability, $K_{s m}\left(\mathrm{~m}^{2}\right)$ & $2.09 \times 10^{-18}$ \\
$\alpha_{\mathrm{m}}(1 / \mathrm{pa})$ & $1.35 \times 10^{-6}$ \\
$\beta_{\mathrm{m}}$ & 1.78 \\
Matrix saturated saturation, $S_{s m}$ & 1.0 \\
Matrix residual saturation, $S_{r m}$ & 0.045 \\
Fracture saturated saturation, $\mathrm{S}_{\mathrm{sf}}$ & 1.0 \\
Fracture residual saturation, $S_{r f}$ & 0.0 \\
Fracture aperture, $b(\mathrm{~m})$ & $285 \mu \mathrm{m}$ \\
Fracture spacing, $D(\mathrm{~m})$, where frequency $=1 / D$ & 0.11 \\
Fracture bulk permeability, $k=b^{3} / I 2 D\left(\mathrm{~m}^{2}\right)$ & $1.75 \times 10^{-11}$ \\
Volume of grid block, $V\left(\mathrm{~m}^{3}\right)$ & 0.04235 \\
Fracture porosity, $\phi_{f}(b / D)(-)$ & $2.59 \times 10^{-3}$ \\
Fracture volume in grid block $\left(V \phi_{\mathrm{f}}\right)\left(\mathrm{m}^{3}\right)$ & $1.097 \times 10^{-4}$ \\
Matrix volume in grid block $\left(V\left(1-\phi_{\mathrm{f}}\right)\right)\left(\mathrm{m}^{3}\right)$ & $4.224 \times 10^{-2}$ \\
Distance between fracture and matrix, $d=(D-b) / 6(\mathrm{~m})$ & $1.83 \times 10^{-2}$ \\
No. of matrix blocks per grid block, $\sigma\left(V / D^{3}\right)(-)$ & 31.8 \\
\hline
\end{tabular}


Fracture-matrix connection area on matrix block scale, $A_{\mathrm{f}-\mathrm{m}}^{\prime}=2(D-b)^{2}\left(\mathrm{~m}^{2}\right)$

Fracture-matrix connection area on grid block scale, $A_{\mathrm{f}-\mathrm{m}}=A_{\mathrm{f}-\mathrm{m}}^{\prime} * \sigma\left(\mathrm{m}^{2}\right)$

$7.66 \times 10^{-1}$

Table 4-2 Mean values of properties required for the ECM.

\section{Matrix}

Permeability, $K_{s m}\left(\mathrm{~m}^{2}\right)$

$2.09 \times 10^{-18}$

$\alpha_{\mathrm{m}}(1 / \mathrm{pa})$

$1.35 \times 10^{-6}$

$\beta_{\mathrm{m}}$

1.78

Saturated saturation, $S_{m s}$

1.0

Residual saturation $S_{m r}$

0.0453

Porosity $\phi_{m}$

\section{Fractures}

Permeability, $K_{s f}\left(\mathrm{~m}^{2}\right)$

$6.77 \times 10^{-9}$

$\alpha_{\mathrm{f}}(1 / \mathrm{pa})$

$1.22 \times 10^{-3}$

$\beta_{\mathrm{f}}$

Saturated saturation, $S_{f s}$

1.0

Residual saturation, $S_{f r}$

0.0

Porosity $\phi_{\mathrm{f}}$

$2.59 \times 10^{-3}$

Composite matrix/fracture permeability

Permeability, $K_{s f m}\left(\mathrm{~m}^{2}\right)$

$1.75 \times 10^{-11}$

The initial saturation of all matrix material was set equal to 0.7. The fractures were assumed to be dry. All computational domain boundaries are are assumed to be impermeable except for the region that is in contact with the overlying pond of water that infiltrated the region during the field experiment. To simulate the pond, twenty four additional supply elements were added to the top surface of the region. These elements were connected to both the matrix and fracture elements, Figure 4-4. 


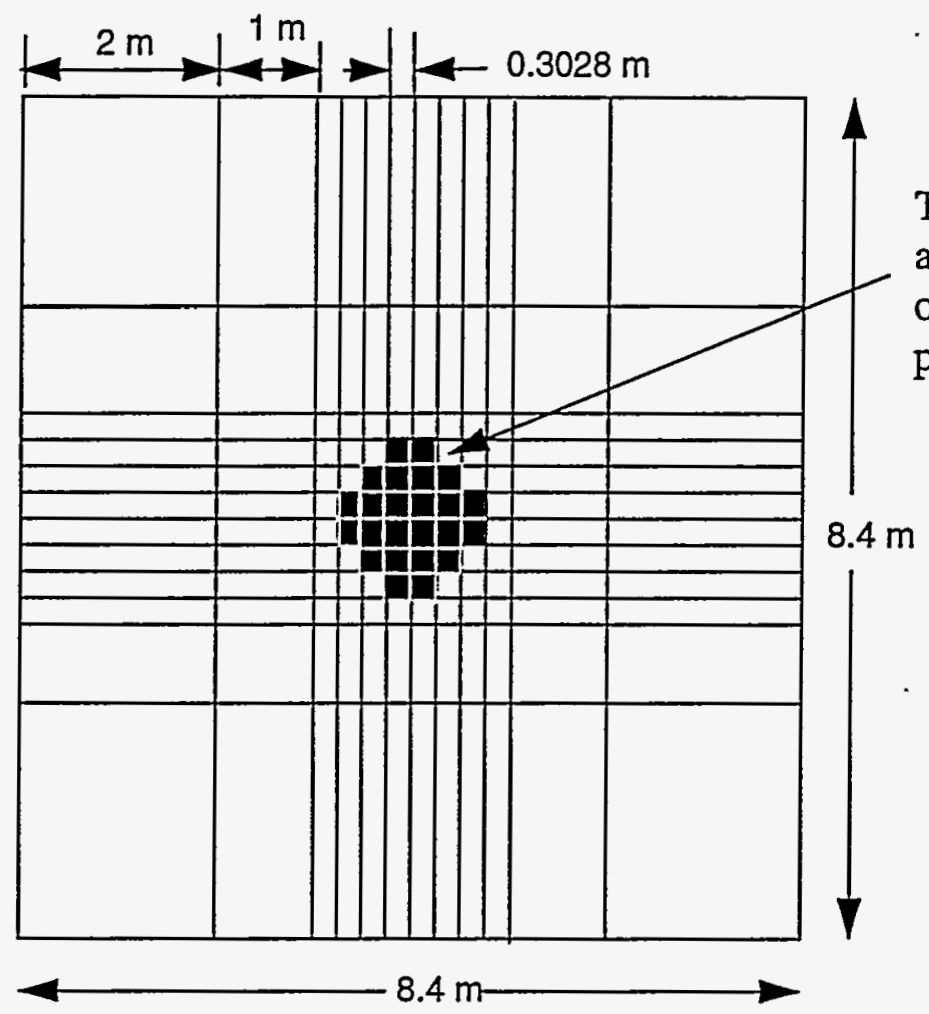

Figure 4-4. Top view of computational mesh showing region of ponded source.

The connection areas were adjusted such that the total connection area for the 24 elements equaled that of the $1.5 \mathrm{~m}$ diameter pond used in the experiment, $1.82 \mathrm{~m}^{2}$

For comparison purposes the infiltration problem was also calculated using the ECM of Peters and Klavetter (1988). The geometry for this problem is generated using MESHMAKER, material option number "9." The material properties for this calculation are given in Table 4-2. The initial and boundary conditions are the same as those used in the DK calculations.

\subsection{Numerical Investigations}

A scoping calculation using the DK model and homogeneous material properties throughout the entire region indicated that a fracture aperture of $285 \mu \mathrm{m}$ would result in an infiltration rate equal to that observed in the field experiment, 205 gallons $\left(0.77 \mathrm{~m}^{3}\right)$ in 36 minutes. This aperture is $50 \%$ larger than the $190 \mu \mathrm{m}$ mean fracture aperture reported for 
the TSw2 material at Yucca Mountain (Wilson, 1995) but considerably smaller that the largest used in their study, $\sim 1000 \mu \mathrm{m}$. Because near surface fracture apertures are likely to control the surface infiltration rate and near surface apertures tend to be larger than those at depth, the $285 \mu \mathrm{m}$ value appears to be a reasonable choice. This value was used for all computations. The series of numerical investigations completed are itemized in Table 4-3.

Table 4-3. Case studies.

Case

1 Base Case, DK model, three-dimensional, 4032 (fracture + matrix) elements, $285 \mu \mathrm{m}$ fractures.

2 Base Case, ECM, three-dimensional, 2016 elements, $285 \mu \mathrm{m}$ fractures.

3 Same as Case 1 except nonhomogeneous fracture properties replaced with mean values based on nonhomogeneous properties.

4 Same as Case 1 except $\mathrm{K}_{\text {matrix }}$ changed to $\mathrm{K}_{\text {matrix, base case }} / 10$.

5 Same as Case 1 except fracture/matrix interaction distances has been reduced, $d_{\text {matrix, base case }}$ changed to $d_{\text {matrix, base case }} / 10$.

6 One-dimensional, one element calculation Investigates fracture/ matrix interactions.

7 One-dimensional, 10 elements, $\Delta x=0.0015 \mathrm{~m}$. Investigates details of fracture/matrix interactions.

Case 1 represents the base case, best estimate, of the matrix and fracture properties using the DK model. The three-dimensional geometry is outlined in Figure 4-1. In Case 1 , the material properties in each element in the core region varied according to the experimentally observed fracture frequencies. The DK model was replaced with the ECM for Case 2. In Case 3, the DK model was used and all core elements were assigned the same material values, that being the mean of the nonhomogeneous core properties. These were the same as the material values used for the buffer region in Case 1 . In Case 4, the permeability of the matrix material was reduced by an order of magnitude, $\left(\mathrm{k}_{\text {matrix }}\right.$ changed to $\mathrm{k}_{\text {matrix, base case }} / 10$ ). This permeability reduction was done to investigate the sensitivity of matrix permeability on infiltration rate. The fracture matrix separation distance, $d$, was reduced by an order of magnitude for Case $5, d_{\text {matrix }}$ changed to $d_{\text {matrix, base case }} 10$. This reduction enhances the fracture matrix interaction. 
To investigate the accuracy of the rate of fracture/matrix water interchange, this flow for two, one-dimensional models was computed, Cases 6 and 7 . In Case 6 , a single fracture and a single matrix element were used, Figure 4-5a. For this case, the fracture matrix separation distance, $d=D / 6=0.0183 \mathrm{~m}\left(\mathrm{x}_{\text {total }}=0.11 \mathrm{~m}\right)$ was the same as was used in the buffer region for the two-dimensional model, Case 1. Case 7 was computed using one fracture element and ten matrix elements, Figure 4-5b. Each element was given a thickness of $0.0015 \mathrm{~m}$ to give an $\mathrm{x}_{\text {total }}=0.015 \mathrm{~m}$. The distance " $\mathrm{d}$ " to the element effective centroid for this case was, $0.75 \times 10^{-3} \mathrm{~m}$, Figure $4-5 \mathrm{~b}$.

(a.)

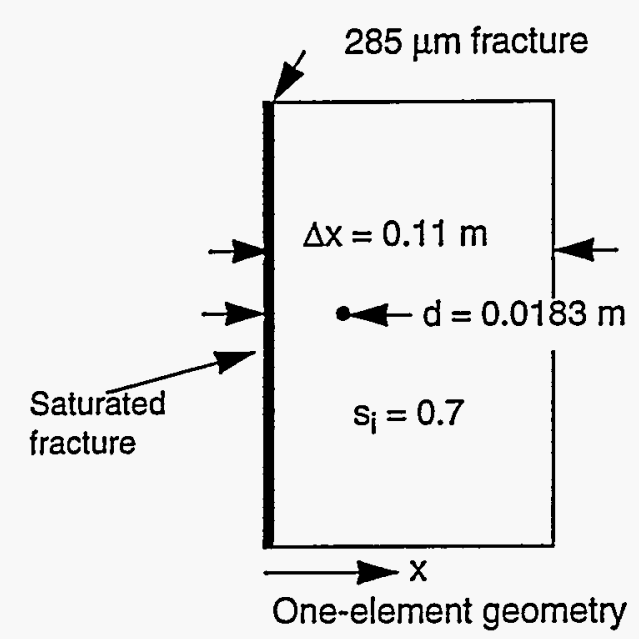

(b.)

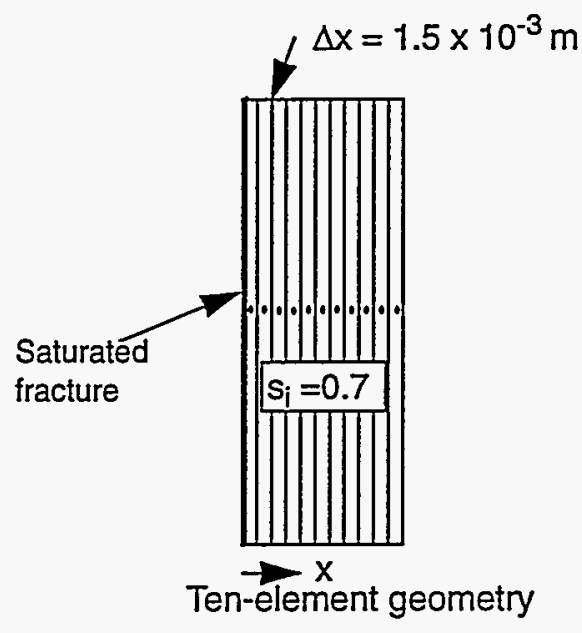

Figure 4-5. Geometry used for one-dimensional infiltration investigations.

\subsection{Summary of Computational Results}

An infiltration rate of 225 gallons in 36 minutes was calculated for the base case, (DK) Case 1. The base case used fracture apertures of $285 \mu \mathrm{m}$, the 640 nonhomogeneous material properties provided by the field observations and the geometry shown in Figures 4-1 through 4-3. The computed infiltration rate is less than $10 \%$ larger than the experimentally observed rate of 205 gallons in 36 minutes. The saturation contours show approximately $40 \mathrm{~m}$ of downward water penetration while imbibition into the matrix is limited, Figures 4-6 and 4-7. 

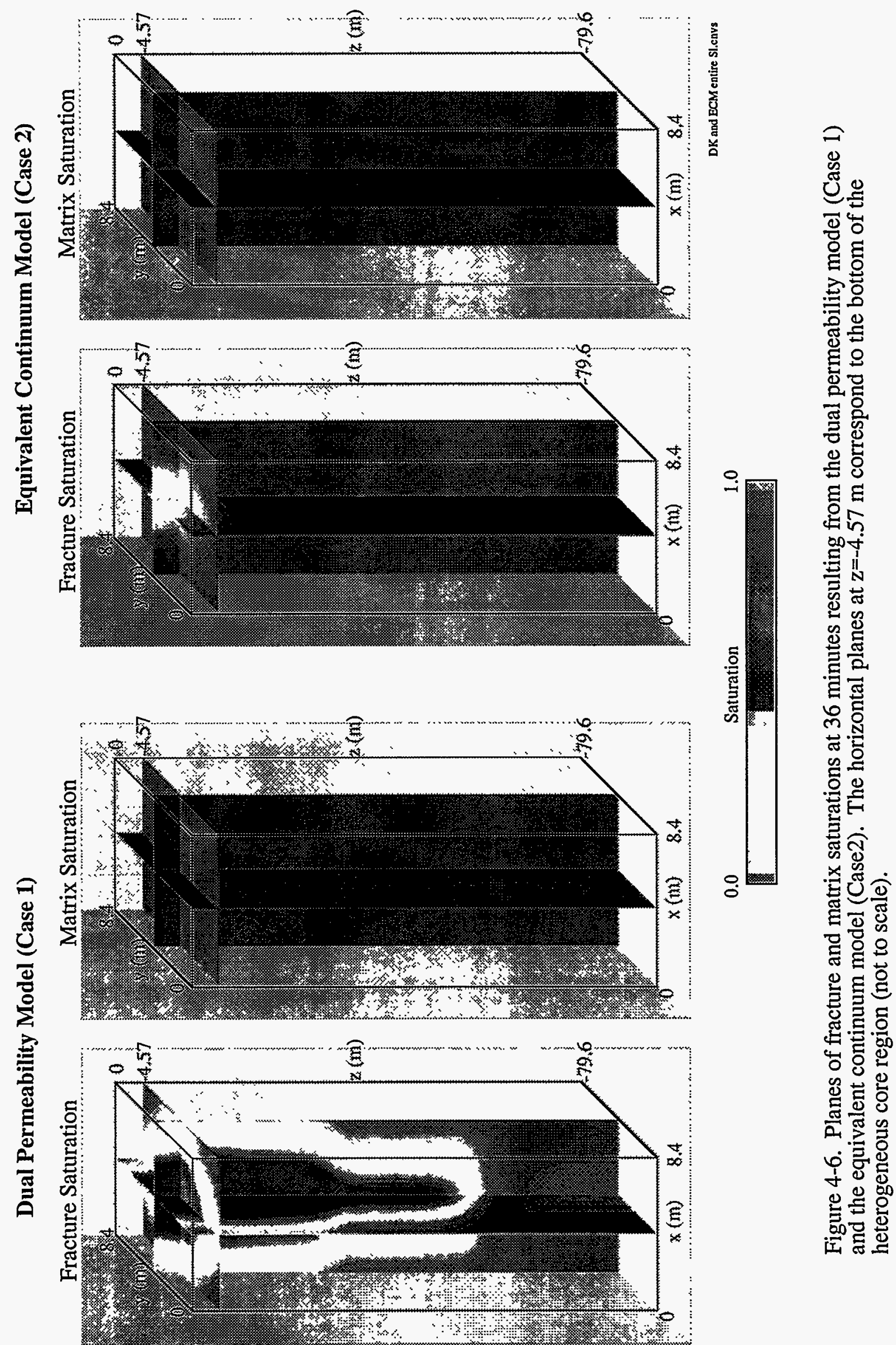

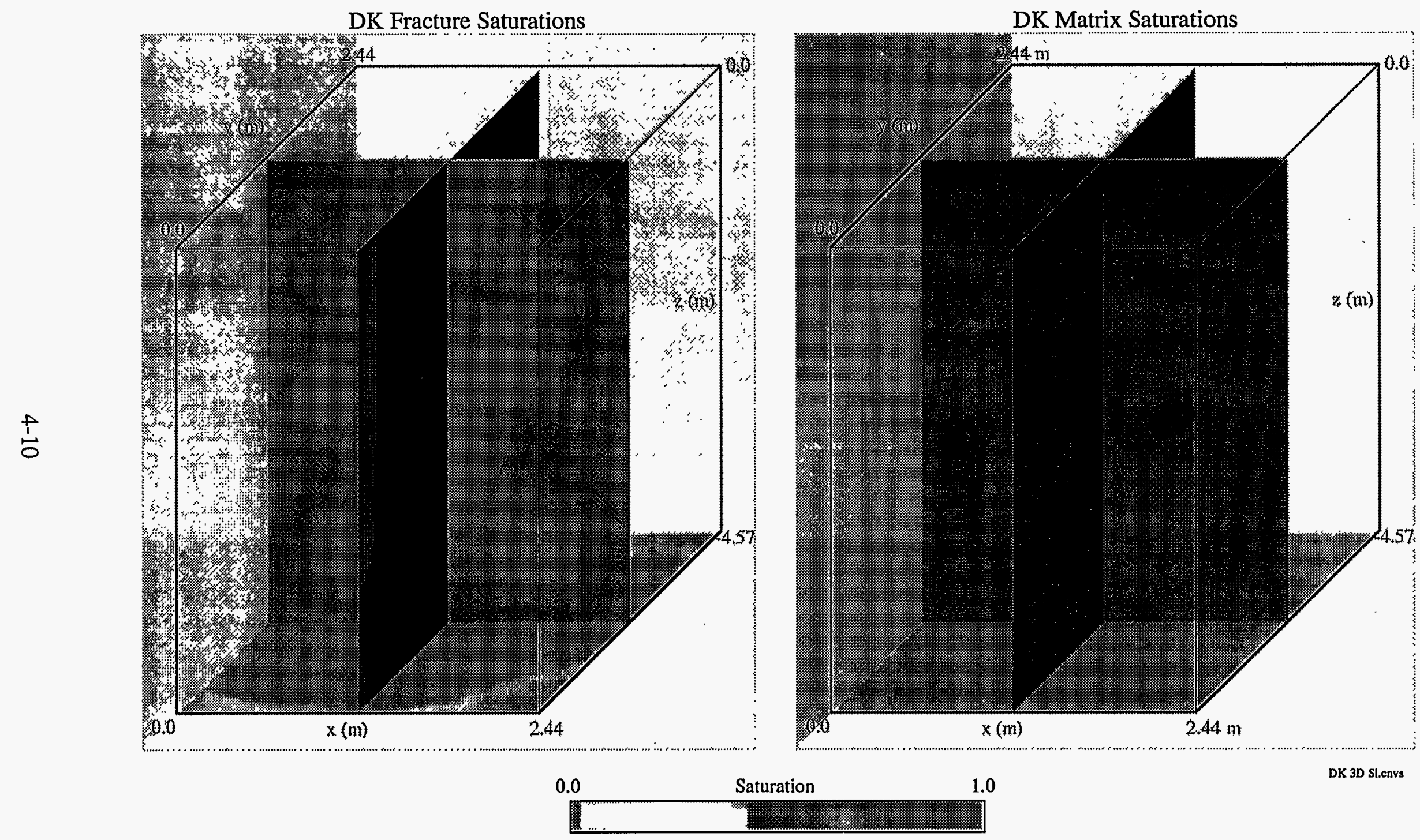

DK 3D Sl.cnvs

Figure 4-7. Planes of fracture and matrix saturations in the core region for Case 1 (DK model base case) at 36 minutes. 
Figure 4-6 demonstrates the significant differences in fracture flow at depth as calculated by the two models. The nonhomogeneous core has a significant effect on the water distribution, Figure 4-7. The resulting vertical matrix and fracture saturations at the middle of the infiltration pond are shown in Figure 4-8.

When the ECM was used, the infiltration rate increased to 503 gallons in 36 minutes, Case 2. This is 2.5 times the experimentally observed value. Because the fracture aperture was calibrated using the DK model it is not surprising that the flow rate calculated using the ECM does not agree with experiment as good as the DK results. The saturation distribution is significantly different as calculated by the two models, Figure 4-6 and 4-9. For the DK case the matrix saturation increase below $3 \mathrm{~m}$ was less than 0.01 . While the saturation in the fractures increased significantly $(\Delta s>0.5)$ to depths of $40 \mathrm{~m}$. This penetration is representative of the experimental fracture penetration indicated by the dye stains which extended to the depth of the excavation. The results given for the ECM are given in terms of composite saturation which includes both the matrix and fractures, Equation 3-1. The fracture penetration calculated by the ECM could be enhanced by arbitrarily decreasing the value of $S_{S}$. This could prove to be a useful way to simulate fracture flow without the add expense of doubling the number of elements as required by the DK model.

The extent of the water penetration into the matrix, $\sim 5 \mathrm{~m}$, for the ECM case is greater than that calculated using the DK model. Using the ECM resulted in more water in the matrix material and less water penetration into the fractures. Table 4-4 gives the fracture/ matrix water distribution for the two cases. Using the DK model results in $60 \%$ of the water in the fractures, while only $4 \%$ ends up in the fractures when using the ECM. The depth of water penetration in the fractures for the $\mathrm{DK}$ model is more representative of what was observed in the field experiments. Little water was observed to penetrate the matrix material and the fractures appeared to experience considerable water flow down to the total excavation depth, $4.6 \mathrm{~m}$.

Table 4-4. Comparison of water distribution using DK and ECM models.

\begin{tabular}{ccccc}
\hline & $\begin{array}{c}\text { vol. in fractures } \\
\left(\mathrm{m}^{3}\right)\end{array}$ & $\begin{array}{c}\text { vol. in matrix } \\
\left(\mathrm{m}^{3}\right)\end{array}$ & $\begin{array}{c}\text { total vol. } \\
\left(\mathrm{m}^{3}\right)\end{array}$ & $\begin{array}{c}\text { \% water in } \\
\text { fractures }\end{array}$ \\
$\begin{array}{c}\text { Case 1 } \\
\text { (DK) }\end{array}$ & 0.51 & .34 & .85 & 60 \\
$\begin{array}{c}\text { Case 2 } \\
\text { (ECM) }\end{array}$ & 0.07 & 1.87 & 1.94 & 4 \\
\hline
\end{tabular}


When the nonhomogeneous materials in the core materials were replaced by the homogeneous buffer material properties, Case 3 , the infiltration rate decreased from 225 for the base case, Case 1, to 193 gallons in 36 minutes, Figure 4-8. The replacement of the heterogeneous media with the homogeneous material resulted in a $14 \%$ reduction of the amount of water that was infiltrated into the region in Case 1. It appears that the use of average material properties gives a reasonable estimate of the infiltration process, but a less accurate estimate of the distribution (infiltration pattern).

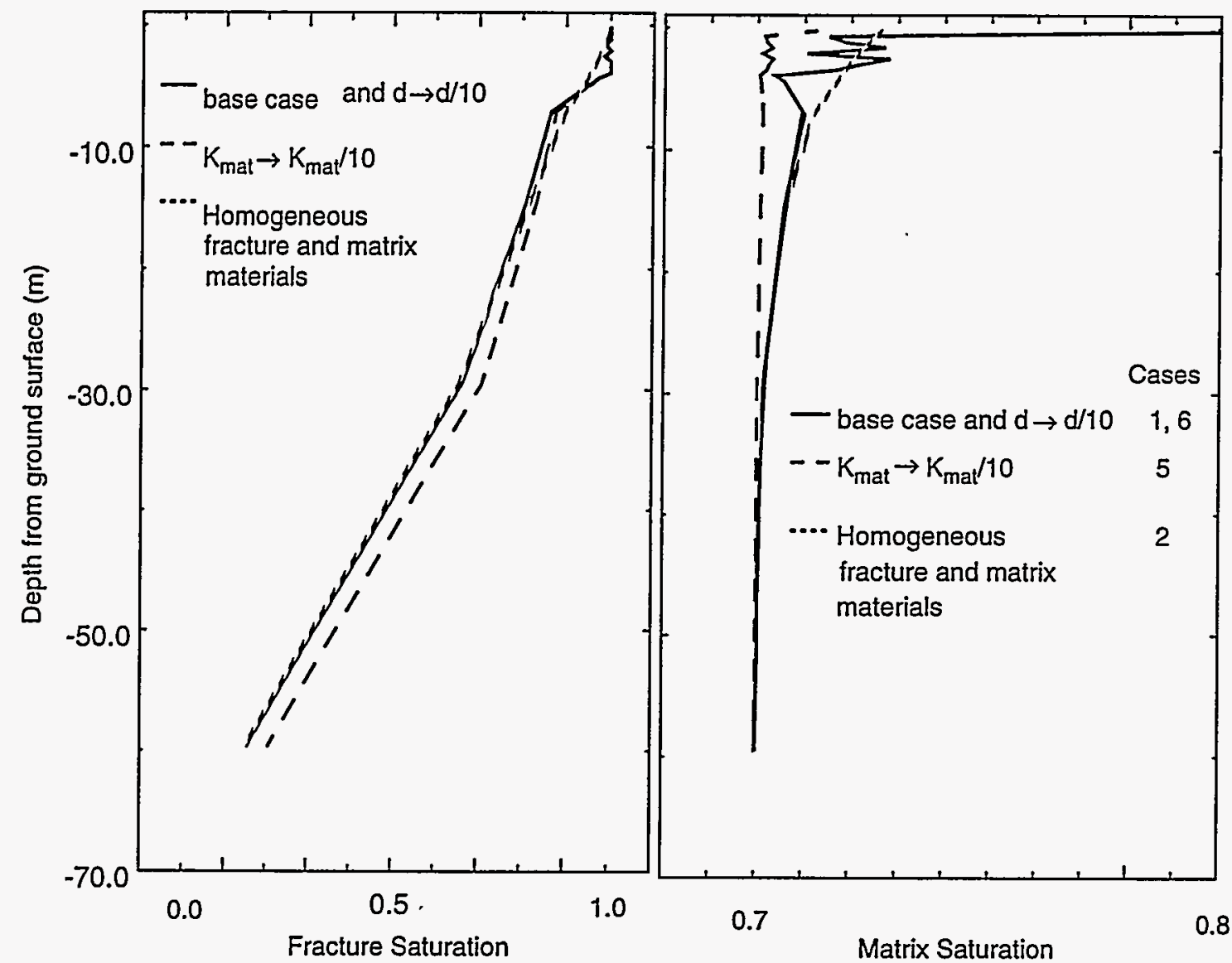

Figure 4-8. Matrix and fracture saturation along vertical centerline of region, for DK simulations, time $=36$ minutes.

In both of these Cases ( 1 and 3 ) the water appears to reside predominately in the fractures for the duration of the relatively short infiltration period, 36 minutes. The fractures, which were initially dry $\left(s_{i}=0.05\right)$, have saturations greater than 0.5 to depths greater than $40 \mathrm{~m}$, while the matrix material saturation has increased less than 0.005 for depths greater than $20 \mathrm{~m}$. This fracture flow is consistent with experimental observations in which little blue dye penetrated the matrix surfaces. 
The permeability of the matrix material was reduced by an order of magnitude in Case 4 to investigate the sensitivity of the infiltration rate to matrix material properties. The infiltration rate for this case was the same as was calculated for the base case, 225 gallons in 36 minutes. In Case 5, the element effective centroid was moved closer to the matrix/ fracture interface by decreasing "d" by an order of magnitude. The infiltration rate was not affected. It was calculated to be 225 gallons in 36 minutes.

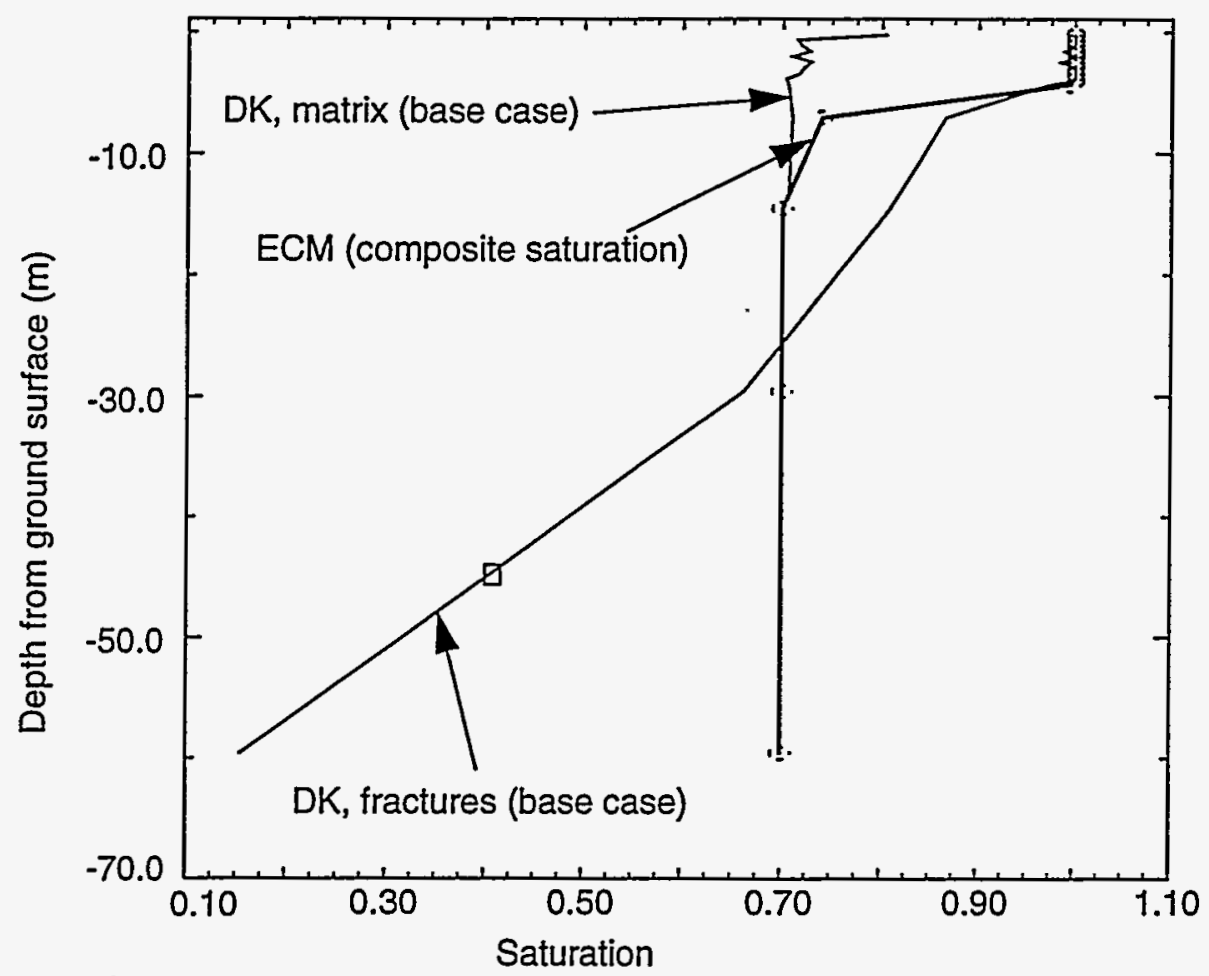

Figure 4-9. Saturation distribution along vertical centerline of region for DK model and $\mathrm{ECM}$ time $=36$ minutes.

It is not clear whether the minimum amount of water calculated to be absorbed into the matrix is realistic or is simply a characteristic of the behavior of the DK method for short time scale, coarse mesh problems. It is probable that the water front, if resolved using a highly refined matrix mesh, would not penetrate as far as the matrix element effective centroid as defined in MINIC as $d=D / 6=0.0183 \mathrm{~m}$. Experience has shown that these are the conditions for which the matrix infiltration rates may be underestimated by an order of magnitude and the applicability of the DK formulation becomes questionable. The applicability of using the DK model for these calculation was investigated using the simplified one-dimensional models shown in Figure 4-5. 
The saturation distribution for these one-dimensional examples, Cases 6 and 7, are given in Figure 4-10. The results, obtained using the refined mesh, show that the penetration of the front into the matrix material 36 minutes after the fracture is saturated is approximately $0.5 \mathrm{~cm}$, Figure 4-10. Visual observation of the blue tracer during excavation implied that the actual penetration of the water into the matrix material was on the order of less than $1 \mathrm{~mm}$, considerably less than the calculated results. It is not clear whether the differences stem from matrix property values, fracture coatings, or matrix/fracture coupling. The amount of water infiltrated into the refined mesh case is only about $50 \%$ more than that calculated for the single matrix element case. This comparison shows that using the distance $d=0.0185 \mathrm{~m}$ to locate the effective centroid of the matrix material is reasonable for fractures that have been exposed to saturated conditions for periods of 36 minutes or longer. However, because it takes time for the front to move down from the surface, many of the fractures at Fran Ridge experienced the saturated condition for periods of time considerably less than 36 minutes. This decreases the accuracy of the calculation due to the fact that the matrix elements were represented by only one element at each location.

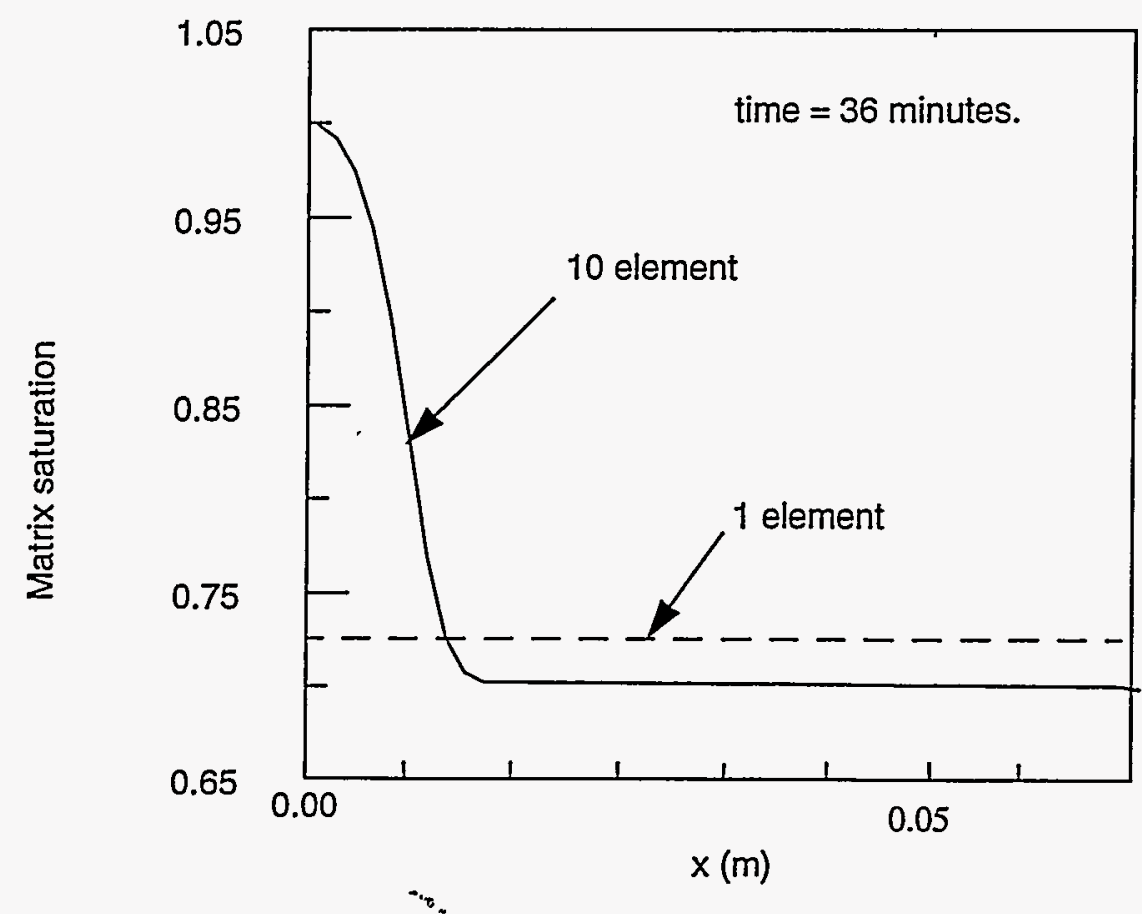

Figure 4-10. Saturation for the one element and 10 element 1-D geometries. 


\section{Conclusions and Recommendations}

\subsection{Conclusions}

These computed flow results obtained using the ECM and the DK models demonstrate the nonuniqueness of these two conceptual models when applied to a specific field experiment. Distinctly different flow patterns were obtained using the two models. The calculated infiltration rates differ by a factor of 2.5. Additionally, the subsurface flow patterns are quite different. Fracture flow dominated when using the DK model and matrix flow dominated when using the ECM. It is not clear the extent that these differences could be minimized as a result of intense code calibration. Specifically, if the value of $S_{m s}$ used in the ECM calculation was decreased to approximately 0.5 , flow into the matrix would be limited and water penetrating the fractures would increase. Thus, agreement between the two models would be enhanced. These exercises demonstrate the continued need for model development and refinement, and for application of conceptual models with the goal being to obtain a better understanding of how to model flow through unsaturated fractured media.

The conclusions regarding the work discussed in this report are itemized as follows.

- Results obtained using the dual permeability model gave a better representation of the flow in the fractures at depth in the Fran Ridge experiment than did the equivalent continuum model results.

- Case 1. The observed infiltration rate was reasonably fitted using as input: (1) 640 experimentally observed fracture frequencies and (2) fracture aperture $=285 \mu \mathrm{m}$.

- Case 2. Using the $285 \mu \mathrm{m}$ fracture aperture, the total water influx for the equivalent continuum model was 2.5 times that calculated using the dual permeability model. Compared to Case 1, the matrix penetration was greater and the fracture penetration was less. 
- Varying the matrix permeability by an order of magnitude changed the in situ matrix and fracture saturation distributions, but did not affect the infiltration rate.

- Reducing the effective element separation distance, $d$, by an order of magnitude, varied the in situ matrix and fracture saturation distributions, but did not affect the infiltration rate

- Based on the two bullets above, it is speculated that the infiltration rate may be dominated by the water pond /porous media coupling or the near surface fracture properties and only weakly coupled to the distribution of fractures at depth.

- In the one-dimensional models, the fracture/matrix flow interchange rate, computed using coarse mesh refinement (one element), was accurate to within 50\%, when compared with refined mesh (ten elements) at 36 minutes. Accuracy would be decreased for shorter times.

\subsection{Recommendations}

The numerical investigations reported in this work aid in the understanding of modeling infiltration into unsaturated, fractured, porous media. A significant portion of performance assessment is coupled with these types of infiltration calculations. Because of its consistancy with observed water distribution in the Fran Ridge experiment the DK model is recommended for use in performance calculations of high-flux infiltration through unsaturated fractured rock.

Although the variation of several of the problem parameters provide some insight to the sensitivity of the parameters that control the rate of infiltration water, this work does not isolate all of the controlling factors. Additional calculations which would add insight to flow in fractured media should be made to focus on; (1) investigating the importance of near surface phenomena (such as the coupling of the ponded surface to the porous media), (2) determining the importance of fracture-matrix connection area, (3) extending the calculations to several days after the infiltration has stopped, (4) set properties of the grid blocks outside the core region heterogeneously using a distribution of consistent with the core, (5) incorporating field observed lateral features cross-cutting the region., and (6) calculating the mesh resolution necessary to adequately predict the infiltration observed in the field experiments that appears to be less than that predicted by current modeling. 


\section{Chapter}

\section{SIX}

\section{References}

Arnold, B. W., S. J. Altman, T. H. Robey, R. W. Barnard, and T. J. Brown, 1995, "Unsaturated-Zone Fast-Path Flow Calculations for Yucca Mountain Groundwater Travel Time Analyses (GWTT-94)," SAND95-0857, Sandia National Laboratories, Albuquerque, NM.

Barnard, R. W., M. L. Wilson, H. A. Dockery, J. H. Gauthier, P. G. Kaplan, R. R. Eaton, F. W. Bingham, and T. H. Robey, 1992, TSPA 1991: An Initial Total-System Performance Assessment for Yucca Mountain, SAND91-2795, Sandia National Laboratories, Albuquerque, NM.

Bassett, R. L., S. P. Neuman, T. C. Rasmussen, A. Guzman, G. R. Davidson, and C. F. Lohrstorfer, 1994, "Validation studies for assessing unsaturated flow and transport through fractured rock," NUREG/CR-6203, U.S. Nuclear Regulatory Commission.

Dudley, A. L., R. R. Peters, J. H. Gauthier, M. L. Wilson, M. S. Tierney, and E. A. Klavetter, 1988, "Total System Performance Assessment Code (TOSPAC) Volume 1: Physical and Mathematical Bases," SAND85-0002, Sandia National Laboratories, Albuquerque, NM. (NNA.881202.0211)

Dykhuizen, R. C., and R. W. Barnard, 1992, "Groundwater Flow Code Verification 'Benchmarking' Activity (COVE-2A): Analysis of Participants' Work," SAND89-2558, Sandia National Laboratories, Albuquerque, NM.

Dykhuizen, R. C., and R. R. Eaton, 1991,"Effect of Material Heterogeneities on Flow Through Porous Media," in Proceedings of the Second Annual International Conference on High Level Radioactive Waste Management, Las Vegas, NV, April 28-May 3, pp. 529534. (NNA.920131.0203)

Fabryka-Martin, J. T., S. J. Wightman, W. J. Murphy, M. P. Wickham, M. W. Cafee, G. J. Nimz, J. R. Souothon, P. Sharma, 1993, "Distribution of Chlorine-36 in the Unsaturated Zone at Yucca Mountain: An Indicator of Fast Transport Paths," published in Conference Proceedings FOCUS '93: Site Characterization and Model Validation, Las Vegas, NV, pp. $58-68$.

Glass, R. J., and V. C. Tidwell, 1991, "Research Program to Develop and Validate Conceptual Models for Flow and Transport Through Unsaturated, Fractured Rock," SAND902261, Sandia National Laboratories, Albuquerque, NM. (NNA.910906.0001) 
Glass, R. J., M. J. Nicholl, and V. C. Tidwell, 1995, "Challenging Models for Flow and Transport in Unsaturated, Fractured Rock Through Exploration of Small Scale Processes," Geophysical Research Letters, Special Issue, Multiphase Flow in Fractured Rock, Vol. 22, No.11,1457-1460.

Ho, C. K., 1995, “Assessing Alternative Conceptual Models of Fracture Flow," Proceedings of the TOUGH Workshop '95, Lawrence Berkeley Laboratory, Berkeley, California, LBL-37200 CONF-9503110.

Klavetter, E. A., and R. R. Peters, 1986, "Estimation of Hydrologic Properties of an Unsaturated Fractured Rock Mass," SAND84-2642, Sandia National Laboratories, Albuquerque, NM. (NNA.870317.0738)

Neuman, S. P., 1987, "Stochastic Continuum Representation of Fractured Rock Permeability as an Alternative to the REV and Fracture Network Concepts," Farmer, I. W. et al. (eds.), Proceedings of the 28th U. S. Svmposium on Rock Mechanics, Balkema, Boston, pp. 533-561.

Nicholl, M. J., and R. J. Glass, 1995, "Effective Media Models for Unsaturated Fractured Rock: A Field Experiment," in Proceedings of the Sixth Annual International High Level Radioactive Waste Management Conference, Las Vegas, NV, April 30 May 5, pp. 39-40.

Peters, R. R., and E. A. Klavetter, 1988, "A Continuum Model for Water Movement in an Unsaturated Fractured Rock Mass," Water Resources Res., Vol. 24, No. 3, pp. 416-430.

Prindle, R. W., and P. L Hopkins, 1990, "On Conditions and Parameters Important to Model Sensitivity for Unsaturated Flow Through Layered, Fractured Tuff: Results of Analyses for HYDROCOIN Level 3 Case 2," SAND89-0652, Sandia National Laboratories, Albuquerque, NM. (NNA. 911202.0031)

Pruess, K., 1991, "TOUGH2-A General-Purpose Numerical Simulator for Multiphase Fluid and Heat Flow," LBL-29400, Lawrence Berkeley Laboratory, Berkeley, CA. (NNA.940202.0088)

Pruess, K., 1987, “TOUGH User's Guide," SAND86-7104, NUREG/CR-4645, LBL20700, Lawrence Berkeley Laboratory, Berkeley, CA. (NNA.890315.0010)

Pruess, K., and T. N. Narasimhan, 1985, “A Practical Method for Modeling Fluid and Heat Flow in Fractured Porous Media," Societv of Petroleum Engineers Journal, Vol. 25, No. 1, pp. 14-26. (NNA.890522.0235)

Pruess, K., 1983, "GMINC--A Mesh Generator for Flow Simulations in Fractured Reservoirs," LBL-15227, Lawrence Berkeley Laboratory, Berkeley, CA. (HQS. 880517.1859) 
Reeves, M., N. A. Baker, and J. O. Duguid, "Review and Selection of Unsaturated Flow Models," Document No. B00000000-01425-2200-00001, Rev. 00, Civilian Radioactive Waste Management System, Management \& Operating Contractor Report, April 4, 1994.

Richards, L. A., 1931, "Capillary Conduction of Liquids Through Porous Mediums," Physics, Vol. 1, pp. 318-333.

Robey, T. H., 1994, "Development of Models for Fast Fluid Pathways Through Unsaturated Heterogeneous Porous Media," SAND93-7109, Sandia National Laboratories, Albuquerque, NM.

Russell, C.E., J.W. Hess, and S.W. Tyler, 1987, "Hydrogeologic Investigations of Flow in Fractured Tuffs, Rainier Mesa, Nevada Test Site, in Flow and Transport Through Unsaturated Fractured Rock," Geophysical Monograph 42, American Geophysical Union, Washington, D.C., pp. 43-50.

van Genuchten, M. Th., 1980, "A Closed-Form Equation for Predicting the Hydraulic Conductivity of Unsaturated Soils," Soil Sci. Soc. Am. J., Vol. 44, No. 5, pp. 892-898 (NNA.890522.0287)

Wilson, M. L., J. H. Gauthier, R. W. Barnard, G. E. Barr, H. A. Dockery, E. Dunn, R. R. Eaton, D. C. Guerin, N. Lu, M. J. Martinez, R. Nilson, C. A. Rautman, T. H. Robey, B. Ross, E. E. Ryder, A. R. Schenker, S. A. Shannon, L. H. Skinner, W. G. Halsey, J. D. Gansemer, L. C. Lewis, A. D. Lamont, I. R. Triay, A. Meijer, and D. E. Morris, 1994, "TotalSystem Performance Assessment for Yucca Mountain -- SNL Second Iteration (TSPA1993)," SAND93-2675, Sandia National Laboratories, Albuquerque, NM.

\section{Data References}

Sandia National Laboratories, 1995, "Infiltration Data Obtained During Flow Visualization Experiment at Fran Ridge," DTN: SNL19011590003.004.

Sandia National Laboratories, 1995, "Pavement Maps Associated with Fran Ridge Flow Visualization Test,” DTN: SNL19011590003.005.

Sandia National Laboratories, 1995, "Extraction of Fracture Trace Length and Orientation From Fran Ridge Pavement Maps," DTN: SNL19011590003.006.

Sandia National Laboratories, 1995, "Fracture Frequency from Fran Ridge Pavement Maps," DTN: SNT05090195001.001. 


\section{YUCCA MOUNTAIN SITE CHARACTERIZATION PROJECT}

\section{UC814 - DISTRIBUTION LIST .}

1

D. A. Dreyfus (RW-1)

Director

OCRWM

US Department of Energy

1000 Independence Avenue SW

Washington, DC 20585

1 L. H. Barrett (RW-2)

Acting Deputy Director

OCRWM

US Department of Energy

1000 Independence Avenue SW

Washington, DC 20585

1 S. Rousso (RW-40)

Office of Storage and Transportation

OCRWM

US Department of Energy

1000 Independence Avenue SW

Washington, DC 20585

1 R. A. Milner (RW-30)

Office of Program Management

and Integration

OCRWM

US Department of Energy

1000 Independence Avenue SW

Washington, DC 20585

1 D. R. Elle, Director

Environmental Protection Division

DOE Nevada Field Office

US Department of Energy

P.O. Box 98518

Las Vegas, NV 89193-8518

1 T. Wood (RW-14)

Contract Management Division

OCRWM

US Department of Energy

1000 Independence Avenue SW

Washington, DC 20585

4 Victoria F. Reich, Librarian

Nuclear Waste Technical Review Board

1100 Wilson Blvd., Suite 910

Arlington, VA 22209

5 Wesley Barnes, Project Manager

Yucca Mountain Site Characterization

Office

US Department of Energy

P.O. Box $98608-\mathrm{MS} 523$

Las Vegas, NV 89193-8608
1 Director

Office of Public Affairs

DOE Nevada Operations Office

US Department of Energy

P.O. Box 98518

Las Vegas, NV 89193-8518

8

Technical Information Officer

DOE Nevada Operations Office

US Department of Energy

P.O. Box 98518

Las Vegas, NV 89193-8518

1

P. K. Fitzsimmons, Technical Advisor Office of Assistant Manager for Environmental Safety and Health DOE Nevada Operations Office US Department of Energy P.O. Box 98518

Las Vegas, NV 89193-8518

1

J. A. Blink

Deputy Project Leader

Lawrence Livermore National Laboratory

101 Convention Center Drive

Suite 820, MS 527

Las Vegas, NV 89109

2

J. A. Canepa

Technical Project Officer - YMP

N-5, Mail Stop J521

Los Alamos National Laboratory

P.O. Box 1663

Los Alamos, NM 87545

1 Repository Licensing \& Quality

Assurance

Project Directorate

Division of Waste Management

US NRC

Washington, DC 20555

1

Senior Project Manager for Yucca

Mountain

Repository Project Branch

Division of Waste Management

US NRC

Washington, DC 20555

1

NRC Document Control Desk

Division of Waste Management

US NRC

Washington, DC 20555 
1 Chad Glenn

NRC Site Representative

301 E Stewart Avenue, Room 203

Las Vegas, NV 89101

1

E. P. Binnall

Field Systems Group Leader

Building 50B/4235

Lawrence Berkeley Laboratory

Berkeley, CA 94720

1 Center for Nuclear Waste

Regulatory Analyses

6220 Culebra Road

Drawer 28510

San Antonio, TX 78284

2 W. L. Clarke

Technical Project Officer - YMP

Attn: YMP/LRC

Lawrence Livermore National Laboratory

P.O. Box 5514

Livermore, CA 94551

1 V.R. Schneider

Asst. Chief Hydrologist - MS 414

Office of Program Coordination

and Technical Support

US Geological Survey

12201 Sunrise Valley Drive

Reston, VA 22092

1 J. S. Stuckless, Chief

Geologic Studies Program

MS 425

Yucca Mountain Project Branch

US Geological Survey

P.O. Box 25046

Denver, CO 80225

$1 \quad$ N. Z. Elkins

Deputy Technical Project Officer

Los Alamos National Laboratory

Mail Stop 527

101 Convention Center Drive, \#820

Las Vegas, NV 89109

2 Michaele C. Brady

Technical Project Officer - YMP

Sandia National Laboratories

Organization 6302, MS 1399

101 Convention Center Drive, Suite 880

Las Vegas, NV 89102

1 Ray Waillace

US Geological Survey

106 National Center

12201 Sunrise Valley Drive

Reston, VA 22092

1 L. R. Hayes
Technical Project Officer

Yucca Mountain Project Branch

MS 425

US Geological Survey

P.O. Box 25046

Denver, CO 80225

1

A. L. Flint

US Geological Survey

MS 721

P.O. Box 327

Mercury, NV 89023

1 R. E. Lewis

Yucca Mountain Project Branch

MS 425

US Geological Survey

P.O. Box 25046

Denver, CO 80225

1 D. Zesiger

US Geological Survey

101 Convention Center Drive

Suite 860, MS 509

Las Vegas, NV 89109

2 L. D. Foust

Nevada Site Manager

TRW Environmental Safety Systems

101 Convention Center Drive

Suite P-110, MS 423

Las Vegas, NV 89109

1 C. E. Ezra

YMP Support Office Manager

EG\&G Energy Measurements Inc.

MS V-02

P.O. Box 1912

Las Vegas, NV 89125

1 E. L. Snow, Program Manager

Roy F. Weston, Inc.

955 L'Enfant Plaza SW

Washington, DC 20024

1 Technical Information Center

Roy F. Weston, Inc.

955 L'Enfant Plaza SW

Washington, DC 20024

1 Technical Project Officer - YMP

US Bureau of Reclamation

Code D-3790

P.O. Box 25007

Denver, CO 80225 
1

B. T. Brady

Records Specialist

US Geological Survey

MS 421

P.O. Box 25046

Denver, CO 80225

$1 \quad$ M. D. Voegele

Technical Project Officer - YMP

$\mathrm{M \& O} / \mathrm{SAIC}$

101 Convention Center Drive

Suite 407

Las Vegas, NV 89109

1 Paul Eslinger, Manager

PASS Program

Pacific Northwest Laboratories

P.O. Box 999

Richland, WA 99352

1 A. T. Tamura

Science and Technology Division

OSTI

US Department of Energy

P.O. Box 62

Oak Ridge, TN 37831

1 P. J. Weeden, Acting Director

Nuclear Radiation Assessment Div. US EPA

Environmental Monitoring Sys. Lab

P.O. Box 93478

Las Vegas, NV 89193-3478

1 ONWI Library

Battelle Columbus Laboratory

Office of Nuclear Waste Isolation

505 King Avenue

Columbus, OH 43201

1 C. H. Johnson

Technical Program Manager

Agency for Nuclear Projects

State of Nevada

Evergreen Center, Suite 252

1802 N. Carson Street

Carson City, NV 89710

1 John Fordham, Deputy Director

Water Resources Center

Desert Research Institute

P.O. Box 60220

Reno, NV 89506

1 The Honorable Cyril Schank

Chairman

Churchill County Board of

Commissioners

190 W. First Street

Fallon, NV 89406
T. Hay, Executive Assistant

Office of the Governor

State of Nevada

Capitol Complex

Carson City, NV 89710

3

R. R. Loux

Executive Director

Agency for Nuclear Projects

State of Nevada

Evergreen Center, Suite 252

1802 N. Carson Street

Carson City, NV 89710

1 Brad R. Mettam

Inyo County Yucca Mountain

Repository Assessment Office

P. O. Drawer L

Independence, CA 93526

1 Lander County Board of Commissioners

315 South Humbolt Street

Battle Mountain, NV 89820

1 Vernon E. Poe

Office of Nuclear Projects

Mineral County

P.O. Box 1600

Hawthome, NV 89415

1 Les W. Bradshaw

Program Manager

Nye County Nuclear Waste Repository

Project Office

P.O. Box 1767

Tonopah, NV 89049

1 Florindo Mariani

White Pine County Coordinator

P. O. Box 135

Ely, NV 89301

1 Judy Foremaster

City of Caliente Nuclear Waste

Project Office

P.O. Box 158

Caliente, NV 89008

1 Philip A. Niedzielski-Eichner

Nye County Nuclear Waste

Repository Project Office

P.O. Box 221274

Chantilly, VA 22022-1274 
1 Dennis Bechtel, Coordinator Clark County Nuclear Waste Div. 500 S. Grand Central Parkway Suite 3012

Las Vegas, NV 89155-1751

1 Juanita D. Hoffman

Nuclear Waste Repository

Oversight Program

Esmeralda County

P.O. Box 490

Goidfield, NV 89013

1 Eureka County Board of Commissioners Yucca Mountain Information Office P.O. Box 714

Eureka, NV 89316

1 Economic Development Dept.

City of Las Vegas

400 E. Stewart Avenue

Las Vegas, NV 89101

1 Community Planning \& Development City of North Las Vegas

P.O. Box 4086

North Las Vegas, NV 89030

1 Community Development \& Planning

City of Boulder City

P.O. Box 61350

Boulder City, NV 89006

1 Commission of European Communities 200 Rue de la Loi

B-1049 Brussels

BELGIUM

2 Librarian

YMP Research \& Study Center

MS 407

P.O. Box 98521

Las Vegas, NV 89193-8521

1 Amy Anderson

Argonne National Laboratory

Building 362

9700 S. Cass Avenue

Argonne, IL 60439

$1 \quad$ Glenn Van Roekel

Director of Community Development City of Caliente

P.O. Box 158

Caliente, NV 89008
G. S. Bodvarsson

Head, Nuclear Waste Department

Lawrence Berkeley Laboratory

1 Cyclotron Road, MS 50E

Berkeley, CA 94720

1 Michael L. Baughman

Intertech Services Corp.

P.O. Box 93537

Las Vegas, NV 89193

MS

21330

C. B. Michaels, 6352

$100 /$

/SAND

20

1330 NWMT Library, 6352

$19018^{\circ}$ Central Technical Files, 8523-2

50899 Technical Library, 13414

$10619 \quad$ Print Media, 12615

20100 Document Processing, 7613-2 for DOE/OSTI 


\begin{tabular}{|c|c|c|}
\hline 2 & MS 1330 & $\begin{array}{l}\text { C. B. Michaels, } 6352 \\
\text { 100/12543/SAND }\end{array}$ \\
\hline & MS 133 & G. M. Gerstner-Miller \\
\hline & & Data Set: 51/L21-08/01/94 \\
\hline & MS $1330^{-}$ & WMT Library, 6352 \\
\hline 1 & MS 9018 & Central Technical Files, $8523-2$ \\
\hline 5 & MS 0899 & Technical Library, 13414 \\
\hline 1 & MS 0619 & Technical Publications, 12615 \\
\hline 2 & 0100 & $\begin{array}{l}\text { Document Processing for } \\
\text { DOE/OSTI, 7613-2 }\end{array}$ \\
\hline 1 & MS 1324 & P. B. Davies, 6115 \\
\hline 1 & MS 1326 & H. A. Dockery, 6312 \\
\hline 1 & MS 1326 & S. Altman, 6312 \\
\hline 3 & MS 1326 & B. Arnold, 6312 \\
\hline 1 & MS 1326 & R. Barnard, 6312 \\
\hline 1 & MS 1326 & G. Barr, 6312 \\
\hline 1 & MS 1326 & J. Gauthier, 6312 \\
\hline 1 & MS 1326 & M. Wilson, 6312 \\
\hline 1 & MS 1325 & L. Costin, 6313 \\
\hline 1 & MS 1325 & R. Finley, 6313 \\
\hline 1 & MS 1325 & E. Ryder, 6313 \\
\hline 1 & MS 1325 & S. Sobolik, 6313 \\
\hline 1 & MS 1324 & P. Davies, 6115 \\
\hline 1 & MS 1324 & M. Cromer, 6115 \\
\hline 3 & MS 1324 & R. Glass, 6115 \\
\hline 5 & MS 1324 & C. K. Ho, 6115 \\
\hline 1 & MS 1324 & S. McKenna, 6115 \\
\hline 3 & MS 1324 & M. Nicholl, 6115 \\
\hline 1 & MS 1324 & V. Tidwell, 6115 \\
\hline 1 & MS 1324 & S. Webb, 6115 \\
\hline 1 & MS 1324 & J. Woodruff, 6115 \\
\hline 1 & MS 0841 & P. Hommert, 9100 \\
\hline 1 & MS 0826 & W. Hermina, 9111 \\
\hline 1 & MS 0834 & A. Ratzel, 9112 \\
\hline 10 & MS 0834 & R. Eaton, 9112 \\
\hline & MS 0826 & S. Gianc \\
\hline
\end{tabular}




\section{Chapter SEVEN}

\section{Rib Appendix}

\section{Information from the Reference Information Base Used in this Report}

This report contains no information from the Reference Information Base.

\section{Candidate Information for the Reference Information Base}

This report contains no candidate information for the Reference Information Base.

\section{Candidate Information for the}

\section{Geographic Nodal Information Study and Evaluation System}

This report contains no candidate information for the Geographic Nodal Information Study and Evaluation System 